\title{
Resiliency-Driven Approach of DC Microgrid Voltage Regulation Based on Droop Index Control for High Step-Up DC-DC Converter
}

\author{
Ram Babu Thogaru $\mathbb{D}^{1},{ }^{1}$ Dipanshu Naware $\mathbb{D}^{1},{ }^{1}$ Arghya Mitra ${ }^{(D)}{ }^{1}$ \\ and Jeetendra Chaudhary (iD) ${ }^{2}$ \\ ${ }^{1}$ Department of Electrical Engineering, Visvesvaraya National Institute of Technology, Nagpur (M.S.)-440010, India \\ ${ }^{2}$ Department of Electrical Engineering, IOE Pulchowk Campus, Tribhuvan University, Kirtipur, Nepal \\ Correspondence should be addressed to Jeetendra Chaudhary; jeetendra@ioe.edu.np
}

Received 22 October 2021; Revised 3 December 2021; Accepted 20 December 2021; Published 31 January 2022

Academic Editor: Pawan Sharma

Copyright $\odot 2022$ Ram Babu Thogaru et al. This is an open access article distributed under the Creative Commons Attribution License, which permits unrestricted use, distribution, and reproduction in any medium, provided the original work is properly cited.

Regulation of DC microgrid voltage in presence of variable sources and loads is quite challenging. The ability of a microgrid to pay off the critical loads when subjected to disturbances, such as utility grid outage/poor climatic conditions, has gained importance recently. To address the above issues, we propose a resiliency analysis of a DC microgrid interconnected with $400 \mathrm{~V}$ and $200 \mathrm{~V}$ buses. The interconnected microgrid system is fed with solar PV along with the energy storage system and is integrated with a utility grid. Boost and high step-up DC-DC converters are employed for DC bus voltage regulation with droop index control. Here, the droop coefficient is optimized using particle swarm optimization (PSO) while maintaining uninterrupted service to critical loads and for satisfactory voltage regulation. The effectiveness of the droop index control method is tested in comparison to other optimization techniques and also with the conventional method. The resiliency analysis of the overall system, aiming for continuous power supply to the critical loads while maintaining the grid voltage unaffected, is carried out in grid outage, low solar insolation, and grid restoration conditions. The reliability of the interconnected DC microgrid test system is evaluated using the loss of power supply probability index for normal, grid outage, and grid restoration conditions. The system is implemented using PSCAD/EMTDC platform. Finally, the experimental prototype of a high step-up DC-DC converter is developed and tested to validate the effectiveness of the droop index controller with an optimized droop coefficient.

\section{Introduction}

The concept of microgrid involves eco-friendly renewable energy technologies like solar PV, wind, bio-generator, fuel cells, and energy storage system (ESS) that offers clean and efficient distributed generation operating at low voltage level. With the integration of renewable energy sources, stability, reliability, efficiency, and security become major concerns [1]. A microgrid that has the potential to operate in both grid-tied or isolated mode has sought the attention of researchers to understand the need for a modern-day grid in the environment [2]. The advantages of DC microgrid over AC can be reiterated with the fact that solar PV and ESS work with DC. The optimal design of microgrid, addressing the merits of DC over AC, is documented [3]. The study suggests that the overall cost and size of ESS are reduced to a great extent. The continually increasing interest in DC microgrid over its AC counterpart is due to the fact that it is highly reliable and efficient and has a natural interface with distributed energy sources, electronic loads, and ESS. The exponentially growing power electronics technologies have allowed devices to operate at both medium and high-level power applications.

With the expansion in the number of DC microgrids, their control aspect is quite challenging. A comprehensive review on various control strategies in hybrid AC/DC microgrid is reported [4] where an extensive review covering various aspects such as modeling, energy management, and stability analysis is presented. Similarly, a DC microgrid with both grid and islanded modes is studied in detail [5] by conducting case studies to validate the resilience-based efficacy of the proposed approach. The authors in [6] implemented a resiliencybased approach by incorporating a battery energy storage 
system (BESS) with the existing grid-connected microgrid to address the critical loads (CLs) during grid outage conditions to ensure stable operation of hybrid AC/DC microgrid. Furthermore, to make the distribution system robust from natural disasters, optimal sizing and placement of distributed generators are assessed [7] with PSO by prioritizing the restoration of critical loads. Load power sharing and bus voltage regulation are the two well-known control objectives possessed by the DC microgrid. A consensus-based algorithm is demonstrated [8] with constant current, constant impedance, and constant power loads (CPLs) simultaneously and validated through simulation. Furthermore, in [9], a multiinput/output nonlinear dynamic model was developed for regulating voltage and MPPT control in a DC microgrid, whereas to study the qualitative behavior of droop control characteristics and MPPT, a novel static model approach was proposed in [10].

Current sharing and voltage regulation are the key aspects in a distributed generation; hence, their control is quite challenging. The authors in [11] made use of communication technology to exchange information to achieve regulated voltage and current sharing proportionately. The CPL causes instability in the system as it offers negative impedance. The current through the CPL increases when the voltage across it decreases and vice versa. To overcome this problem, a nonlinear control scheme was discussed [12] based on passivity-based control as it guarantees system stability. On the other hand, an energy management scheme for local energy communities with residential consumers in a DC microgrid was documented in [13] with a closed-loop controlled high-gain DC-DC converter. The required regulation is achieved with an appropriate control algorithm adopted for the system.

A modern-day microgrid is equipped with DC-DC converters while a high step-up DC-DC converter based on coupled inductor is the feasible option. The performance analysis of the same is demonstrated [14] which differs from the traditional one with the addition of integrated regenerative snubber and soft-switching conditions. Furthermore, a hybrid DC-DC converter with high voltage gain is proposed [15] that combines a conventional coupled inductor-based boost converter with different techniques for the switched capacitor. The highly efficient performance of the hybrid converter is achieved experimentally. For bidirectional power flow applications, a similar approach has been presented [16] to achieve a highvoltage conversion ratio. It integrates coupled inductor with a switched capacitor to attain high efficiency. It also displays the advantage such as wide-voltage gain and switching at zero voltage. Moreover, the design/testing aspect of a high-gain high-power DC-DC converter was portrayed in [17] with the comparative study based on key performance parameters.

Optimization has always been the backbone of electrical power systems. Right from evaluating the optimal cost of generating units at the service provider end for economic load dispatch to determining the optimal cost of electricity at the consumer's end, optimization has played a crucial role in the existing grid. As we are inching towards a green and sustainable grid, there has been a manifold increase in the importance of optimization techniques. Its various application areas involve energy management system, demand response, sizing of BESS, microgrid stability, and so on [18]. The authors in [19] comprehensively reviewed the application of PSO in a microgrid. Minimum operating cost related to energy management, optimal power flow, and so on is evaluated for different microgrid models based on its operating performance, whereas economic dispatch of power in conjunction with various distributed energy sources is optimized with teaching-learning-based optimization (TLBO) [20].

However, voltage regulation and current sharing are the major issues as discussed in the literature above that mostly focuses on control strategies of conventional DC-DC converters and are feasible for low-voltage microgrids. Future microgrid comes with high-power applications, which are addressed here. A high step-up DC-DC converter is proposed for a parallel-connected DC microgrid. Also, dynamic loads (DC shunt motor) and CPLs have been introduced here along with static loads.

This work encompasses the following:

(i) A resiliency-based novel framework is established for a parallel-connected DC microgrid with a high step-up DC-DC converter for uninterrupted supply to the CLs.

(ii) A swarm-based intelligence algorithm is used to optimize the droop coefficient.

(iii) The loss of power supply probability is evaluated for assessing reliability of the system under normal and outage conditions.

(iv) A hardware prototype of the high step-up DC-DC converter is developed and tested with a proposed droop index controller.

This paper is structured as follows. Modeling of $400 \mathrm{~V}$ and $200 \mathrm{~V}$ bus DC microgrids with different components is given in Section 2. The analysis and design of the droop index controller are presented in Section 3. The resiliency analysis of DC microgrids with different case studies is considered in Section 4. Experimental results and analysis are given in Section 5. Section 6 gives conclusive remarks.

\section{System Modeling}

A single high-power converter is not worthy enough as compared to a parallel-connected one in a microgrid environment interfaced through power electronics devices. Figure 1 shows an interconnected DC microgrid based on solar PV with $400 \mathrm{~V}$ and $200 \mathrm{~V}$ buses integrated with resistive loads, DC shunt motor loads (specifications are mentioned in Table 1), constant power loads, battery energy storage, and utility grid (UG). These loads are divided as critical loads (CLs) and noncritical loads (NCLs). In the absence of a utility grid due to fault or natural calamity and/ or absence or reduction of solar PV power due to sudden climatic change, CL needs to be supplied before NCL on the corresponding buses. If NCL on the DC bus remains intact 


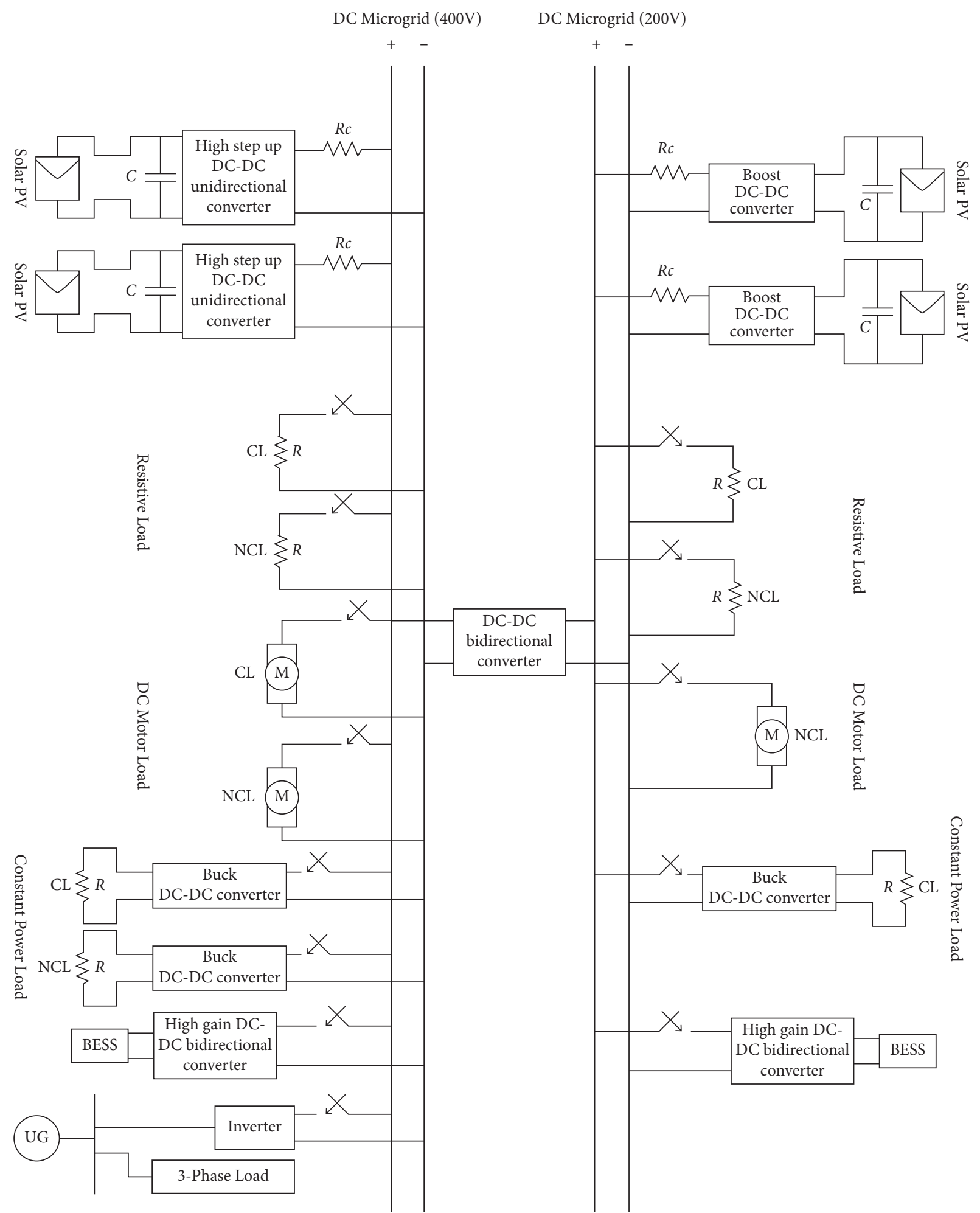

FIgURE 1: Solar PV-based $400 \mathrm{~V}$ and $200 \mathrm{~V}$ DC microgrids with the utility grid, BESS, and loads (static load, dynamic load, and CPL).

under disturbance, there will be a fall in DC bus voltage, which may affect the performance of the DC microgrid. To overcome this problem, there is a need to connect a temporary power source to maintain the bus voltage within the satisfactory limit and, at the same time, to make the system resilient against the sudden disturbance that occurred.
Improvement of DC microgrid voltage is achieved with the droop index method, proposed for high step-up and boost DC-DC converter. Two DC microgrids with $400 \mathrm{~V}$ and $200 \mathrm{~V}$ ratings are connected through a bidirectional converter. Each DC microgrid has parallel-connected PV modules, high step-up and high-gain high-efficiency 
TABLE 1: DC shunt motor specifications $[34,35]$.

\begin{tabular}{lccc}
\hline \multirow{2}{*}{ Symbols } & Parameters & \multicolumn{2}{c}{ Values } \\
& & On $400 \mathrm{~V}$ bus side converter & On 200 V bus side converter \\
\hline$R_{a}$ & DC shunt motor armature resistance & $2.5 \mathrm{Ohms}$ & $1.8 \mathrm{Ohms}$ \\
$R_{f}$ & DC shunt motor field resistance & $250 \mathrm{Ohms}$ & $225 \mathrm{Ohms}$ \\
$L_{a}$ & DC shunt motor armature inductance & $0.01 \mathrm{mH}$ & $0.016 \mathrm{mH}$ \\
$K_{v}$ & Back electromotive force constant & $1.28 \mathrm{~V} / \mathrm{rad} / \mathrm{s}$ & $1.23 \mathrm{~V} / \mathrm{rad} / \mathrm{s}$ \\
$J$ & Mass moment of inertia & $0.0465 \mathrm{Kg} \mathrm{m}{ }^{2}$ & $0.0543 \mathrm{Kg} \mathrm{m}{ }^{2}$ \\
$B_{m}$ & Viscous friction coefficient & $0.0687 \mathrm{~N}-\mathrm{m} / \mathrm{rad} / \mathrm{s}$ & $0.0492 \mathrm{~N}-\mathrm{m} / \mathrm{rad} / \mathrm{s}$ \\
$V_{a}$ & DC shunt motor armature voltage & $400 \mathrm{~V}$ & $200 \mathrm{~V}$ \\
$I_{a}$ & Armature current of DC shunt motor & $2.4 \mathrm{~A}$ & $1.5 \mathrm{~A}$ \\
$I_{f}$ & Field current DC shunt motor & $1.6 \mathrm{~A}$ & $0.9 \mathrm{~A}$ \\
\hline
\end{tabular}

bidirectional DC-DC converters, DC-DC boost converters, BESS, utility grid, CL, and NCL, implemented in PSCAD/ EMTDC software. The effectiveness of the droop index method used in the DC microgrid is established with the help of simulation results for different loading conditions. Table 2 shows the PV-BESS specifications considered for the study.

2.1. Load Modeling. The loads integrated with the DC microgrid are static load, dynamic load, and CPL. The buck converter loaded by CPL is explained below.

2.1.1. Buck Converter Loaded by CPL. The simplest type of converter is to scale down the unregulated DC voltage to regulated output DC voltage. The energy stored by the inductor $L$ is used to maintain the continuous output. It consists of the switch $(S)$, freewheeling diode $\left(D_{F}\right)$, inductor $(L)$, and capacitor $(C)$. During the turn-on period, current flows to the load via the inductor, and energy is stored in it, whereas during the turn-off period, energy stored by the inductor is released via a diode. Two switching modes of operation, namely, continuous and discontinuous modes, are supported by this converter. Figure 2 shows the buck converter loaded by CPL [21]. The design specifications of the DC-DC buck converter are presented in [22]. Table 3 represents the buck converter specifications.

The instability caused by CPL is mainly due to the negative impedance exhibited by CPL as depicted in Figure 3. Due to the invariably negative incremental impedance, the current through the CPL increases when the voltage across it decreases and vice versa. The closed-loop system loaded by CPL helps to stabilize the overall system.

\subsection{DC-DC Converters}

2.2.1. High Step-Up Unidirectional DC-DC Converter. DC-DC converters have always been the backbone in distributed generation applications. A high step-up converter based on coupled inductor is a reasonable choice and is actively adopted in modern-day microgrids. Figure 4 shows the high step-up converter topology [23], used here for the connection of solar PV to the $400 \mathrm{~V}$ bus. It consists of two switches, namely, the main switch $S_{m}$ and the auxiliary switch $S_{\text {aux }}$, input inductor $L_{\text {in }}$, primary and secondary
TABle 2: PV-BESS specifications.

\begin{tabular}{lcc}
\hline \multirow{2}{*}{ Parameters } & \multicolumn{2}{c}{ Values } \\
& $400 \mathrm{~V}$ bus side & $200 \mathrm{~V}$ bus side \\
\hline Series-connected modules & 2 & 2 \\
Parallel-connected strings & 9 & 2 \\
Module with series-connected & 48 & 48 \\
cells & 5 & 6 \\
Parallel cells/modules & $1000 \mathrm{~W} / \mathrm{m}^{2}$ & $1000 \mathrm{~W} / \mathrm{m}^{2}$ \\
Nominal irradiation & $25^{\circ} \mathrm{C}$ & $25^{\circ} \mathrm{C}$ \\
Reference cell temperature & $20 \mathrm{Ah}$ & $20 \mathrm{Ah}$ \\
Rated capacity & $40 \mathrm{~V}$ & $20 \mathrm{~V}$ \\
Battery minimum voltage & $50 \mathrm{~V}$ & $24 \mathrm{~V}$ \\
Battery maximum voltage &
\end{tabular}

windings of the coupled inductance $\left(N_{p}\right.$ and $\left.N_{s}\right)$, blocking capacitor $C_{b}$, clamp capacitor $C_{c}$, capacitor $C_{m}$, diode $D_{m}$, output diode $D_{o}$, and output capacitor $C_{D C}$. An ideal transformer with a turn's ratio of $N\left(=N_{s} / N_{p}\right)$, a magnetizing inductance $L_{m}$, and the leakage inductance $L_{k}$ constitutes a coupled inductor. To increase the voltage conversion ratio of the converter, a voltage multiplier cell with $D_{m}$ and $C_{m}$ is employed. For clamp circuit, $C_{c}$ and $S_{\text {aux }}$ are placed to clamp the voltage spike realized during the turn-off process. Hence, the energy delivered by $L_{k}$ is reprocessed to $C_{c}$, while the voltage stress of $S_{m}$ and $S_{\text {aux }}$ is imposed as the capacitor voltage $C_{c}$. Additionally, the energy retrieved by $L_{k}$ will be dispatched to boost the converter voltage gain [23]. The distinct advantages include lowvoltage stress experienced by the power switches, ultrahigh voltage gain, and low ripple continuous input current, hence making it a suitable candidate for renewable energy applications in the present-day microgrid.

Moreover, zero voltage switching for $S_{m}$ and $S_{\text {aux }}$ can be achieved by exploiting the energy dispatched by $L_{k}$. Furthermore, the output diode experiences reverse recovery which can be mitigated with the help of $L_{k}$ which in turn controls the falling rate of output diode current.

The voltage gain of the high step-up unidirectional converter is given as

$$
M=\frac{V_{\mathrm{DC}}}{V_{\mathrm{PV}}}=\frac{2 N-1}{(N-1)(1-D)},
$$

where $V_{\mathrm{DC}}$ is the high-gain converter output voltage, $V_{\mathrm{PV}}$ is the output voltage of solar PV, $N$ is the number of turns in 


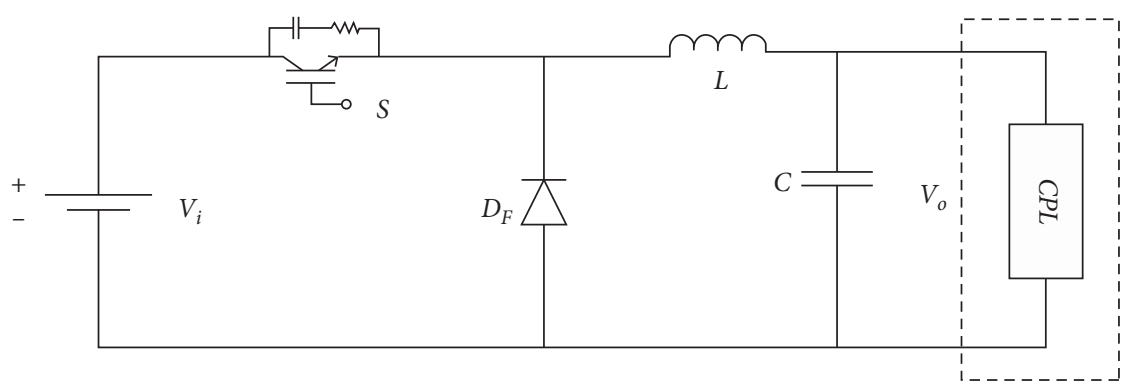

FIGURE 2: Buck converter loaded by CPL [21].

TABle 3: Buck converter specifications.

\begin{tabular}{lccc}
\hline Symbol & Parameter & \multicolumn{2}{c}{ Values } \\
& & $400 \mathrm{~V}$ bus side & $200 \mathrm{~V}$ bus side \\
\hline$V_{i}$ and $V_{o}$ & Input and output voltages of converter & $400 \mathrm{~V}$ and $200 \mathrm{~V}$ & $200 \mathrm{~V}$ and $100 \mathrm{~V}$ \\
$L$ & Filter inductance & $0.426 \mathrm{mH}$ & $0.285 \mathrm{mH}$ \\
$C$ & Filter capacitance & $4 \mu \mathrm{H}$ & $2.6 \mu \mathrm{H}$ \\
$f_{s w}$ & Switching frequency & $50 \mathrm{kHz}$ & $50 \mathrm{kHz}$ \\
\hline
\end{tabular}

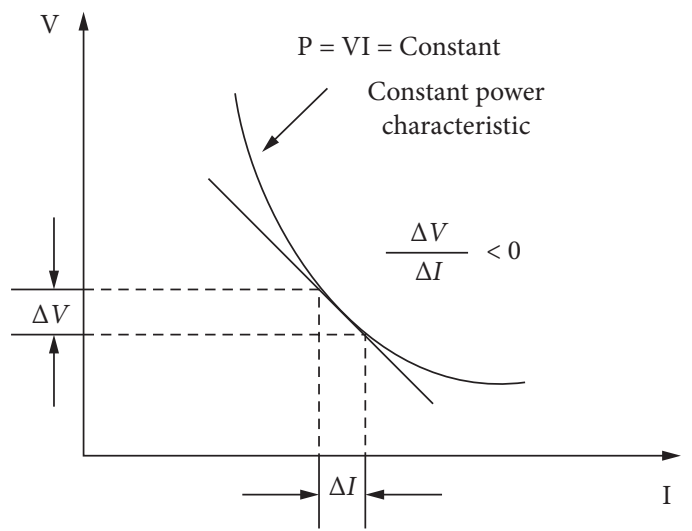

FIGURE 3: I-V characteristics of CPL.

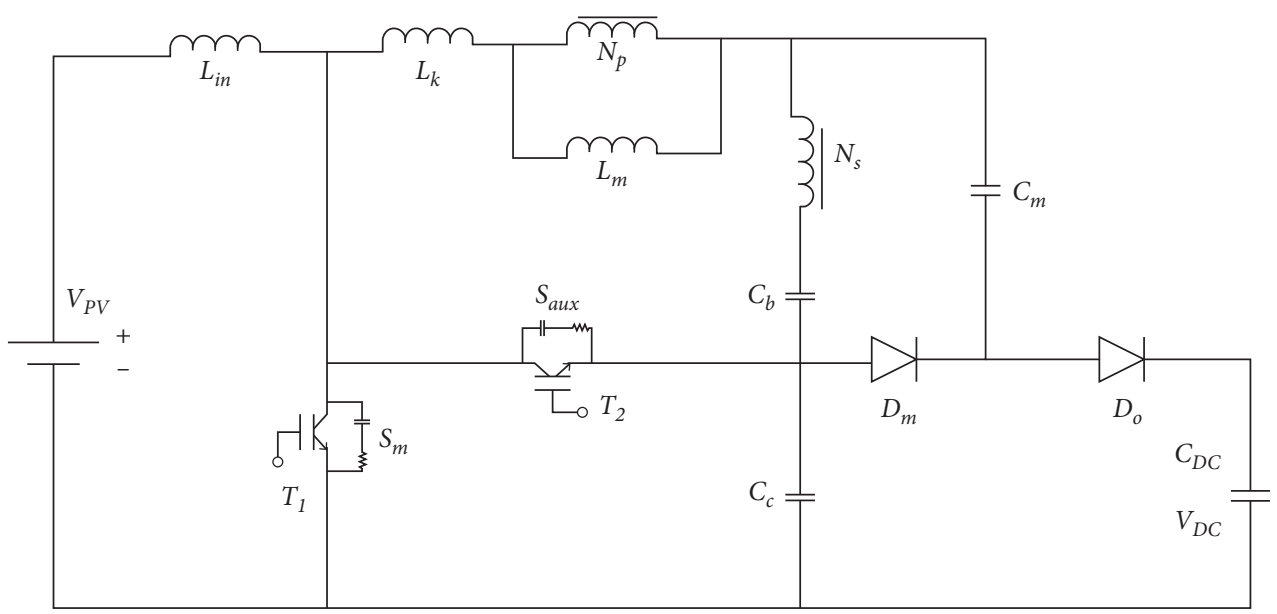

FIgURE 4: High step-up unidirectional DC-DC converter [23]. 
the coupled inductor of high step-up converter, and $D$ is the duty ratio.

The input inductance can be given by

$$
L_{\mathrm{in}}=\frac{D * V_{\mathrm{PV}}}{\Delta I_{L_{\mathrm{in}}} f_{s w}},
$$

where $\Delta I_{L_{\text {in }}}$ is the allowable ripple current. The coupled inductor magnetizing inductance $\left(L_{m}\right)$ is

$$
L_{m} \geq \frac{(1-D)^{2} D^{2} R_{L}}{4 N(2 N-1) f_{s w}},
$$

where $f_{s w}$ is the switching frequency and $R_{L}$ is the load resistance, respectively. Output capacitor $C_{o}$ is calculated as follows:

$$
C_{o}=\frac{I_{\mathrm{DC}} D}{\Delta V_{\mathrm{DC}} f_{s w}} .
$$

The value of the switched capacitor $C_{m}$ is

$$
C_{m}=\frac{V_{\mathrm{DC}}(1-D)}{\Delta V_{c_{m}} f_{s w}} .
$$

The value of the blocking capacitor $C_{b}$ is

$$
C_{b}=\frac{(1-D)^{2}}{\pi^{2} L_{k} f_{s w}^{2}} .
$$

The value of the capacitor $C_{c}$ is ascertained as

$$
C_{c}=\frac{N I_{\mathrm{DC}}}{2(N-1) D f_{s w} \Delta V_{c_{c}}} .
$$

Table 4 shows the high step-up unidirectional DC-DC converter specifications.

\subsubsection{High-Gain High-Efficiency Bidirectional DC-DC} Converter. Figure 5 shows the high-gain high-efficiency bidirectional DC-DC converter, an extended version of the high-gain high-efficiency unidirectional DC-DC converter [24]. In this converter, to achieve the bidirectional property, a switch $\left(S_{2}\right)$, a diode $\left(D_{4}\right)$, and an inductor $\left(L_{3}\right)$ are merged to extract the aspect of the buck converter. To raise or lower the voltage based on battery voltage levels, it is positioned between the DC bus and BESS. The battery can charge or discharge through a bidirectional converter. Table 5 shows the specifications of the high-gain high-efficiency bidirectional converter used for the study.

The voltage gain of the high-gain converter may be given as

$$
m=\frac{V_{\mathrm{DC}}}{V_{\text {bat }}}=\frac{N_{h}+1}{1-D},
$$

where $V_{\mathrm{DC}}$ is the high-gain converter output voltage, $V_{\text {bat }}$ is the output voltage of the battery, $N_{h}$ is coupled inductor's number of turns in the high-gain converter, and $D$ is converter switch duty cycle.

The minimum value of the clamp capacitor $\left(C_{1}\right)$ is given by
TABle 4: High step-up unidirectional DC-DC converter specifications.

\begin{tabular}{lcc}
\hline Symbol & Parameter & Value \\
\hline$V_{P V}$ and $V_{D C}$ & Input and output voltages & $40 \mathrm{~V}$ and $400 \mathrm{~V}$ \\
$L_{\text {in }}$ & Input inductor & $470 \mu \mathrm{H}$ \\
$L_{m}$ & Magnetizing inductance & $240 \mu \mathrm{H}$ \\
$L_{k}$ & Leakage inductance & $3.1 \mu \mathrm{H}$ \\
$N_{s} / N_{p}$ & Number of turns & $17 / 12$ \\
$C_{b}$ and $C_{c}$ & Blocking and clamp capacitors & $68 \mu \mathrm{F}$ and \\
& & $220 \mu \mathrm{F}$ \\
$C_{m}$ and $C_{o}$ & Switched and output capacitors & $47 \mu \mathrm{F}$ and \\
& Main and auxiliary power & $100 \mu \mathrm{F}$ \\
$S_{m}$ and $S_{\text {aux }}$ & switches & - \\
$D m$ and $D o$ & Diodes & - \\
$f_{s w}$ & Switching frequency & $50 \mathrm{kHz}$ \\
\hline
\end{tabular}

$$
C_{1}=\frac{I_{m} D}{\Delta V_{c 1} f_{s}} .
$$

The minimum value of the intermediate capacitor $\left(C_{2}\right)$ is given by

$$
C_{2}=\frac{I_{m} D}{m \Delta V_{c 2} f_{s}} .
$$

The minimum value of the output capacitor $\left(C_{\mathrm{DC}}\right)$ is given by

$$
C_{\mathrm{DC}}=\frac{I_{\mathrm{DC}} D}{\Delta V_{\mathrm{DC}} f_{s}},
$$

where $I_{m}$ is the magnetizing current, $f_{s w}$ is the switching frequency, $I_{\mathrm{DC}}$ is the high-gain converter output current, $\Delta I_{m}$ is the magnetizing inductance ripple current, $\Delta V_{c 1}$ and $\Delta V_{c 2}$ represent the ripple voltages of clamp and intermediate capacitors, respectively, and $\Delta V_{\mathrm{DC}}$ is the output ripple voltage.

2.2.3. High-Efficiency Bidirectional DC-DC Converter. Switching at zero voltage in a bidirectional DC-DC converter is achieved for all switches by using the resonant circuit. Bidirectional half-bridge type buck-boost topology forms the basis. The additional circuit components include two resonant capacitors, two parallel capacitors, and a resonant inductor.

A highly efficient bidirectional converter operates in two different modes. If switch $S_{2}$ operates as main switch and $S_{1}$ operates as an auxiliary, the converter transfers power from the lesser voltage side $V_{L}$ to higher voltage side $V_{H}$, known as the boost mode, whereas if the switch $S_{1}$ acts as main switch and $S_{2}$ acts as an auxiliary, it transfers power from $V_{H}$ to $V_{L}$, known as the buck mode. Current flowing through anti-parallel diodes causes both switches to operate as shown in Figure 6. Due to low on-state resistance $\left(R_{\mathrm{DS}, \text { on }}\right)$, MOSFET has small conduction losses.

The resonant frequency is given by

$$
\omega_{r}=\frac{1}{\sqrt{L_{r} C_{r}}} .
$$




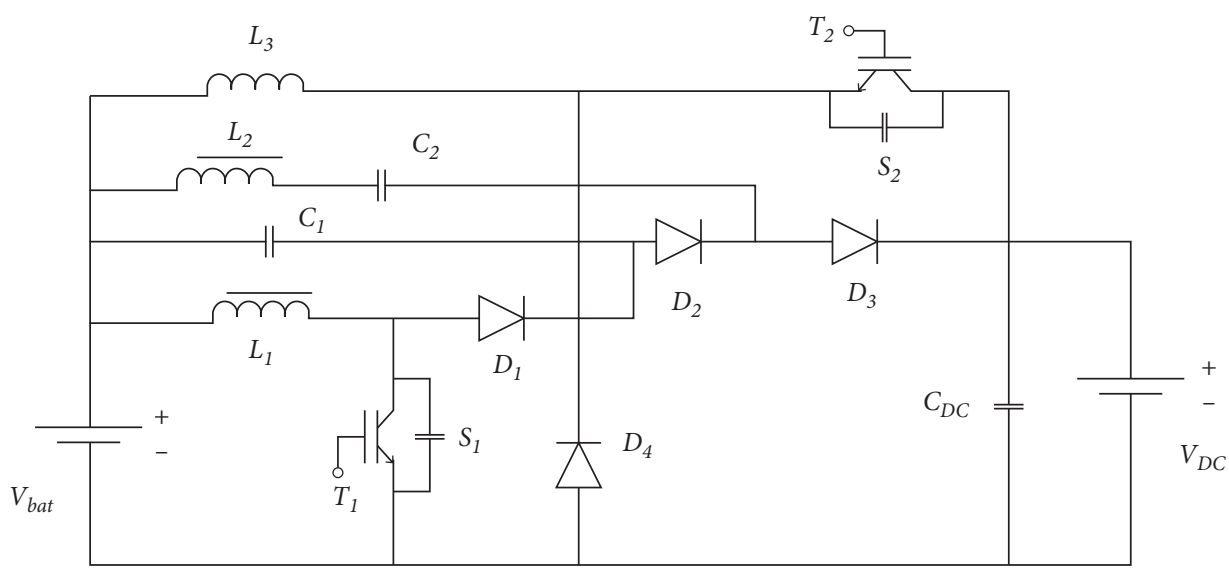

FIgURE 5: High-gain high-efficiency bidirectional DC-DC converter [24].

TABLE 5: High-gain high-efficiency bidirectional DC-DC converter specifications.

\begin{tabular}{lccc}
\hline \multirow{2}{*}{ Symbols } & Parameters & & Values \\
& Coupled inductors & On $400 \mathrm{~V}$ bus side converter & On $200 \mathrm{~V}$ bus side converter \\
\hline$L_{1}$ and $L_{2}$ & Inductor on grid side & $38 \mu \mathrm{H}$ & $38 \mu \mathrm{H}$ \\
$L_{3}$ & Passive clamp network capacitor & $38 \mu \mathrm{H}$ & $38 \mu \mathrm{H}$ \\
$C_{1}$ & Intermediate energy storage capacitor & $40 \mu \mathrm{F}$ & $46 \mu \mathrm{F}$ \\
$C_{2}$ & DC link voltage & $4.2 \mu \mathrm{F}$ & $4.8 \mu \mathrm{F}$ \\
$V_{\mathrm{DC}}$ & Battery voltage & $400 \mathrm{~V}$ & $200 \mathrm{~V}$ \\
$V_{\text {bat }}$ & & $48 \mathrm{~V}$ & $24 \mathrm{~V}$ \\
\hline
\end{tabular}

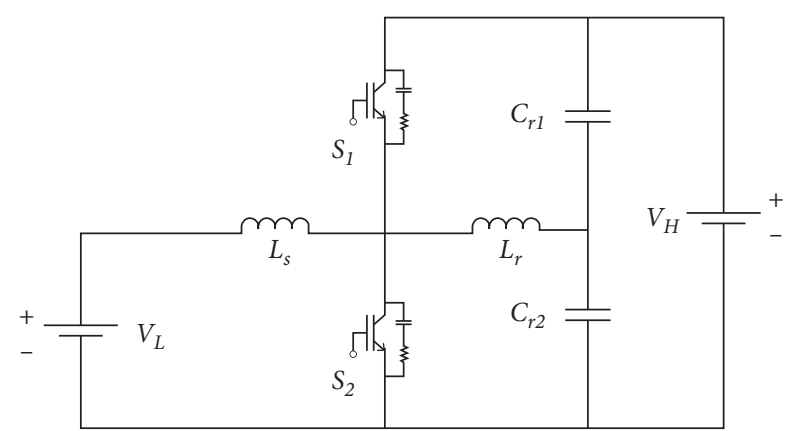

FIGURE 6: High-efficiency bidirectional DC-DC converter [25].

The characteristic impedance is given by

$$
Z_{r}=\sqrt{\frac{L_{r}}{C_{r}}}
$$

The purpose of this converter is to transfer the power from one DC microgrid to another when load demand exceeds generation [25]. Table 6 shows the specifications of high-efficiency bidirectional DC-DC converter.

\section{Controllers}

3.1. Conventional Controller. Figure 7 shows the block diagram representation of the MPPT-based conventional controller. The inputs are the PV voltage $\left(V_{p v}\right)$ and current $\left(I_{p v}\right)$, and the output is $V_{\text {mppt }}$. This output is then compared with the PV voltage $\left(V_{p v}\right)$ which is passed through a PI controller. Moreover, the output of the PI controller is then
TABLE 6: High-efficiency bidirectional DC-DC converter specifications.

\begin{tabular}{lcc}
\hline Symbol & Parameter & Value \\
\hline$L_{s}$ and $L_{r}$ & Main and resonant inductors & $1 \mathrm{mH}$ and $60 \mu \mathrm{H}$ \\
$C_{r 1}$ and $C_{r 2}$ & Resonant capacitors & $10 \mathrm{nF}$ \\
$V_{H}$ and $V_{L}$ & High and low side voltages & $400 \mathrm{~V}$ and $200 \mathrm{~V}$ \\
$f_{s w}$ & Switching frequency & $50 \mathrm{kHz}$ \\
\hline
\end{tabular}

compared with the carrier (triangular) wave to generate the triggering pulses [26].

3.2. Controller with Droop Index Method. The linear increase in converter output current $\left(I_{\mathrm{DC}}\right)$ causes the reference converter output voltage to decrease with the method of droop control.

The reference output voltage in the droop controller is given as

$$
V_{\mathrm{DCref}}=V_{\mathrm{DC}}+I_{\mathrm{DC}} R_{D}
$$

where $V_{\text {DCref }}$ is the setpoint voltage, $V_{\mathrm{DC}}$ is the output voltage of converter, and $R_{D}$ is the droop coefficient of the converter. In absence of cable resistance $\left(R_{c}\right)$, converter output voltage and DC microgrid voltage are the same. If two converters are connected in parallel, then

$\begin{cases}V_{\mathrm{DC} 1}=V_{\mathrm{DC} 2}=V_{L}, & \text { no cable resistance, } \\ V_{\mathrm{DC} 1} \neq V_{\mathrm{DC} 2} \neq V_{L}, R_{c 1} \neq R_{c 2}, & \text { with unequal cable resistance. }\end{cases}$ 


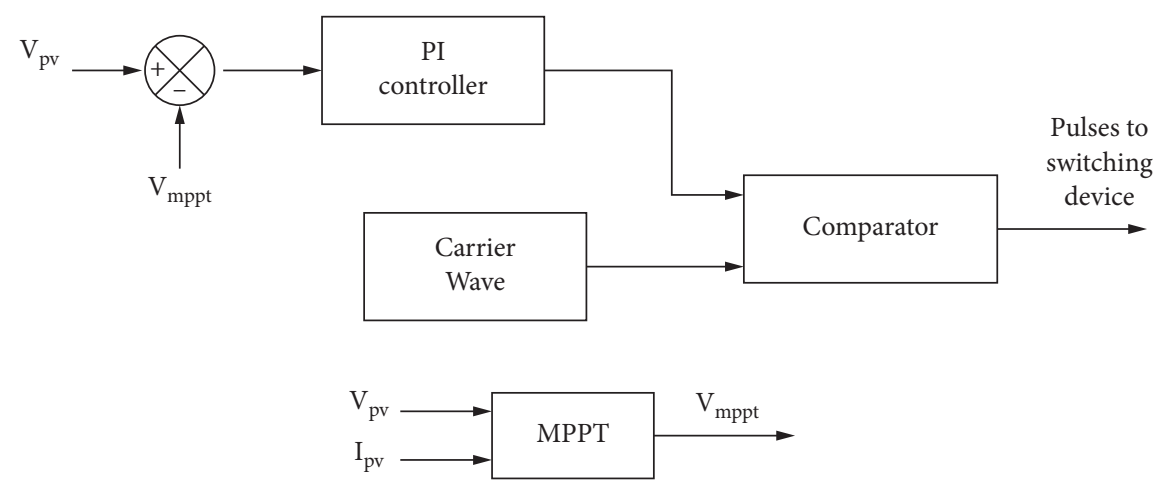

FIgURE 7: Schematic representation of MPPT-based PV control.

Also, in absence of $R_{c}$, the converter output currents become equal when droop resistances are made the same:

$$
\left\{\begin{array}{l}
R_{D 1}=R_{D 2} \longrightarrow I_{\mathrm{DC} 1}=I_{\mathrm{DC} 2} \\
V_{\mathrm{DC} 1}=V_{\mathrm{DC} 2}=V_{L}
\end{array}\right.
$$

By considering cable resistances, the voltage at DC bus is given by

$$
V_{\mathrm{DC}}=V_{\mathrm{DCref}}-I_{\mathrm{DC}}\left(R_{C}+R_{D}\right) .
$$

Therefore, voltage drops corresponding to each converter droop resistance $\left(R_{D 1}=R_{D 2}\right)$ and their associated cable resistance $\left(R_{C 1}=R_{C 2}\right)$ will be the same:

$$
I_{\mathrm{DC} 1}\left(R_{\mathrm{C} 1}+R_{\mathrm{D} 1}\right)=I_{\mathrm{DC} 2}\left(R_{\mathrm{C} 2}+R_{\mathrm{D} 2}\right) \text {. }
$$

Figure 8 (a) depicts the schematic representation of two converters connected to a common node in parallel where $V_{\mathrm{DC} 1}$ and $V_{\mathrm{DC} 2}$ are the output voltages of high step-up DCDC converter-1 and converter-2, respectively, $I_{\mathrm{DC} 1}$ and $I_{\mathrm{DC} 2}$ are the output currents of high step-up DC-DC converter-1 and converter-2, respectively, $R_{D 1}$ and $R_{D 2}$ are the droop coefficients of high step-up DC-DC converter-1 and converter-2, and $R_{C 1}$ and $R_{C 2}$ are the cable resistances of each converter, respectively. The converters supply to a load $R_{L}$ and maintain the voltage across the load at $V_{L}$.

The output impedance of the DC-DC converter reflected by the voltage drop is produced with a droop controller. The proper current sharing is obtained by keeping a suitable droop coefficient which in turn causes deviation of the output of each DC-DC converter voltage [27]. The low value of the droop coefficient improves voltage regulation but deteriorates current sharing and vice versa as shown in Figure 8 (b). For our study, the droop coefficient is optimized for regulating the DC bus voltage.

\subsection{Formulation of the Objective Function to Determine the Optimized Droop Coefficient}

(i) For high step-up DC-DC converter: the output voltage of high step-up converter can be given as

$$
V_{\mathrm{DC}}=\frac{2 N-1}{(N-1)(1-D)} V_{\mathrm{PV}}
$$

Substituting (19) in (14), we get

$$
R_{D}=\frac{(N-1)(1-D) * V_{\mathrm{DCref}}-(2 N-1) * V_{\mathrm{PV}}}{(N-1)(1-D) * I_{\mathrm{DC}}} .
$$

The proposed objective function for the controller of the $i^{\text {th }}$ step-up DC-DC converter is given as follows:

$$
R_{D}=\sum_{i=1}^{n} \frac{(N-1)\left(1-D_{i}\right) * V_{\mathrm{DCref}}-(2 N-1) * V_{\mathrm{PV}}}{(N-1)\left(1-D_{i}\right) * I_{\mathrm{DC} i}},
$$

subject to

$$
\left\{\begin{array}{l}
V_{\mathrm{DCref}}-V_{D C} \leq \Delta v_{\max }, \\
I_{\mathrm{DC} i, \min } \leq I_{\mathrm{DC} i} \leq I_{\mathrm{DC} i, \max } \\
D_{i, \min } \leq D_{i} \leq D_{i, \max }
\end{array}\right.
$$

(ii) For boost converter: similarly, the proposed objective function for the controller of conventional DC-DC boost $i^{\text {th }}$ converter is given as follows:

$$
R_{D}=\sum_{i=1}^{n} \frac{\left(1-D_{i}\right) * V_{\mathrm{DCref}}-V_{\mathrm{PV}}}{\left(1-D_{i}\right) * I_{\mathrm{DC} i}},
$$

subject to

$$
\left\{\begin{array}{l}
V_{\mathrm{DCref}}-V_{\mathrm{DC}} \leq \Delta v_{\max }, \\
I_{\mathrm{DC} i, \min } \leq I_{\mathrm{DC} i} \leq I_{\mathrm{DC} i, \max } \\
D_{i, \min } \leq D_{i} \leq D_{i, \max }
\end{array}\right.
$$

(iii) For high-gain high-efficiency bidirectional DC-DC converter: the output voltage of high-gain highefficiency bidirectional DC-DC converter can be given as

$$
V_{\mathrm{DC}}=\frac{N_{h}+1}{1-D} V_{\text {bat }}
$$

Substituting (25) in (14), we get

$$
R_{D}=\frac{\left(N_{h}+1\right) V_{\mathrm{bat}}-D * V_{\mathrm{DCref}}}{(1-D) * I_{\mathrm{DC}}}
$$




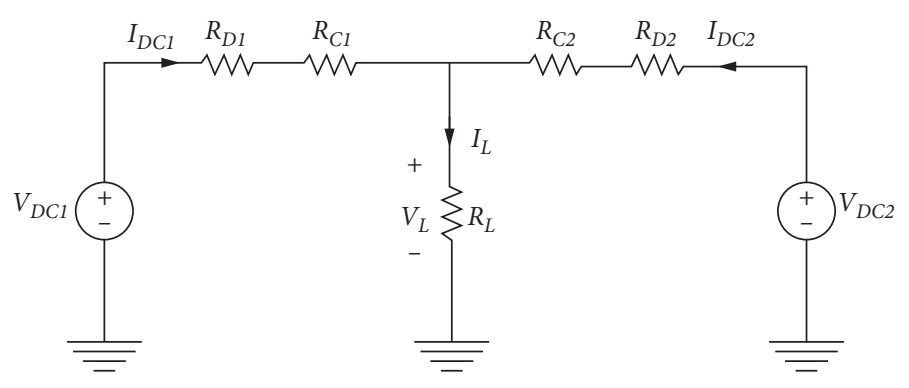

(a)

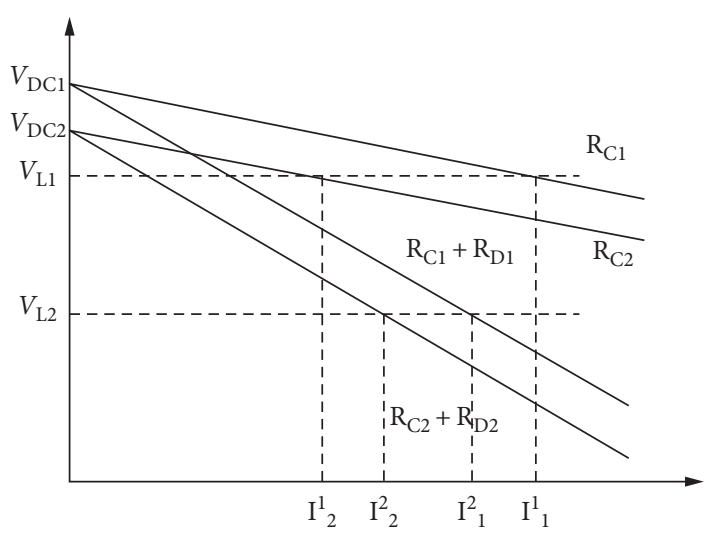

(b)

FIgURE 8: Two parallel-connected DC-DC converters to common node. (a) Equivalent circuit. (b) V-I characteristics.

The proposed objective function for the controller of high-gain high-efficiency bidirectional DC-DC $i^{\text {th }}$ converter is given as follows:

$$
R_{D}=\sum_{i=1}^{n} \frac{\left(N_{h}+1\right) V_{\mathrm{bat}}-D_{i} * V_{\mathrm{DCref}}}{\left(1-D_{i}\right) * I_{\mathrm{DC} i}},
$$

subject to

$$
\left\{\begin{array}{l}
V_{\mathrm{DCref}}-V_{\mathrm{DC}} \leq \Delta v_{\max } \\
I_{\mathrm{DC} i, \min } \leq I_{\mathrm{DC} i} \leq I_{\mathrm{DC} i, \max } \\
D_{i, \min } \leq D_{i} \leq D_{i, \max }
\end{array}\right.
$$

3.4. Selection of a Suitable Optimization Technique. The classical optimization methods help determine the optimal solution and can be categorized as deterministic technique, stochastic technique, and hybrid technique. Several optimization techniques such as cuckoo search, ant colony algorithm, genetic algorithm, whale optimization, and PSO are nature-inspired metaheuristic algorithms. They provide optimal solutions through a population-based iterative process. Among various stochastic methods, PSO is regarded as one of the best-suited algorithms in smart grid applications [28]. It is inspired by the behavior of a swarm searching for food. As it is metaheuristic, random solutions are generated at the initial stage of the iterative process. The swarm-based intelligence generates local and global best solutions for each particle [29]. PSO is governed by mainly two steps: velocity update and position update for each particle, and has few tuning parameters as depicted in $\mathrm{Ta}$ ble 7 which are used in our study.

PSO is governed by the two basic equations as follows:

$$
\begin{aligned}
V_{k}^{i+1}= & w * V_{k}^{i}+C_{1} * r_{1} *\left(X_{\text {pbest }, k}-X_{k}^{i}\right) \\
& +C_{2} * r_{2} *\left(X_{\text {gbest }}-X_{k}^{i}\right), \\
X_{k}^{i+1}= & X_{k}^{i}+V_{k}^{i+1} .
\end{aligned}
$$

Equation (29) represents particle velocity update, and equation (30) indicates position update, where $V_{k}^{i}$ is the current velocity, $X_{\text {pbest, } k}$ and $X_{\text {gbest }}$ are the personal and global best positions of the particles, respectively, $X_{k}^{i}$ is the current particle position, $w$ is the weighing factor, $C_{1}, C_{2}$ are the acceleration coefficients, and $r_{1}, r_{2}$ are random numbers between $[0,1]$.

On the other hand, TLBO is motivated by the teaching and learning process within the classroom ambiance. It is a population (class)-based algorithm and generates the global best solution by an iterative process [30]. Due to the absence of tuning parameters in TLBO, it is preferred over other population-based algorithms like genetic algorithm (crossover, mutation, and selection), artificial bee colony (limit value), and so on. This algorithm is administered by a "teacher phase" and a "learner phase" where the entire population (class) goes through these phases before reaching the optimal solution. Another nature-inspired metaheuristic algorithm, grey wolf optimizer (GWO) [31], operates based on searching, encircling, and attacking prey mechanisms of wolves. Here, the process is governed by alpha, beta, delta, and the omega wolves where alpha is the leader while omega refers to the lowest ranked wolves in the pack. Here, the best three fitness values are saved after each iteration. In our work, PSO, GWO, and TLBO methods are implemented and compared for optimizing the droop coefficient for the converter.

Figure 9 shows the variation of droop coefficient versus iterations using PSO where the optimal value is found to be close to 1.772 for a high step-up DC-DC converter. Similarly, an optimal value of the droop coefficient for the DC-DC boost converter is found to be 1.989 , whereas the optimal value of the droop coefficient for the high-gain high-efficiency DC-DC converter is 8.91. Simulation results indicate the effectiveness of PSO over GWO and TLBO as depicted in Table 8. The processing time indicates the time taken by the algorithm for the same number of population sizes and iterations.

3.5. Droop Control. The optimized droop coefficient $\left(R_{D}\right)$, as obtained using the PSO, is multiplied with the output current and is compared with the reference voltage of the DC 
TABLe 7: PSO parameters.

\begin{tabular}{lcccc}
\hline Parameters & Symbols & High step-up DC-DC converter & DC-DC boost converter & $\begin{array}{c}\text { High-gain high-efficiency DC-DC } \\
\text { converter }\end{array}$ \\
\hline Constant weight & $W_{c}$ & 0.8 & 0.8 & 0.8 \\
Droop resistances & $R_{D, \min }, R_{D, \max }$ & $0.1 \Omega, 2 \Omega$ & $0.1 \Omega, 2.5 \Omega$ & $0.1 \Omega, 10 \Omega$ \\
Voltage references & $V_{\mathrm{DC}, \min }, V_{\mathrm{DC}, \max }$ & $380 \mathrm{~V}, 420 \mathrm{~V}$ & $190 \mathrm{~V}, 210 \mathrm{~V}$ & $380 \mathrm{~V}, 420 \mathrm{~V}$ \\
Acceleration constants & $C_{1}, C_{2}$ & $1.8,1.8$ & $1.8,1.8$ & $1.8,1.8$ \\
Maximum iteration & $J_{\max }$ & 100 & 100 & 100 \\
\hline
\end{tabular}

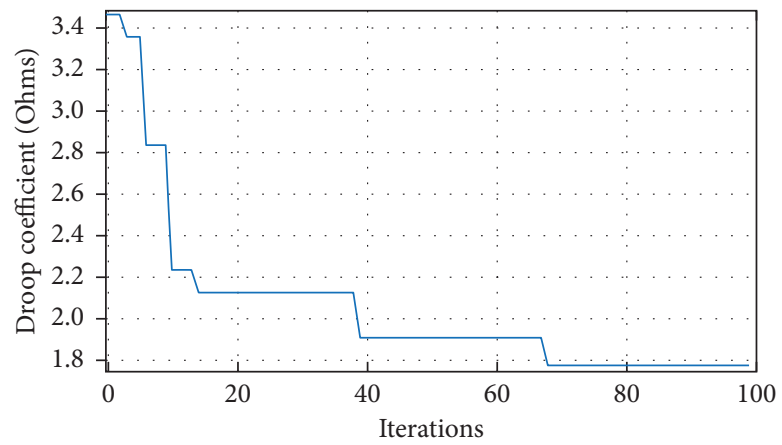

Figure 9: Droop coefficient versus iteration (using PSO).

TABle 8: Comparative results of PSO, GWO, and TLBO.

\begin{tabular}{lcccc}
\hline \multirow{2}{*}{ Algorithms } & \multicolumn{3}{c}{ Optimized droop coefficient $(\Omega)$} & \\
& High step-up DC-DC converter & DC-DC boost converter & High-gain high-efficiency DC-DC converter & Process time $(\mathrm{s})$ \\
\hline PSO & 1.772 & 1.989 & 8.91 & 64.2 \\
GWO & 1.920 & 2.120 & 9.58 & 2.5 \\
TLBO & 1.940 & 2.240 & 9.83 & 29.31 \\
\hline
\end{tabular}

bus $V_{\mathrm{DC} \text {,ref }}$ that generates a new reference, $V_{\mathrm{DC}}^{*}$. This voltage is further matched with the original output voltage of the DC-DC converter. The mismatch generated is passed through the PI controller, which in turn compares its output with the load current $\left(I_{L}\right)$. The error obtained from the first PI controller is passed to the inner-loop PI controller which generates the switching pulses for the respective power switches [32]. The Ziegler-Nichols approach is adopted for tuning the PI controllers. The values of the outer voltage controller of high step-up DC-DC converter $K_{p}$ and $K_{i}$ used for this study are 0.0015 and 0.043 , respectively. The inner current loop is ten times faster than the outer voltage control loop. Similarly, for high-gain high-efficiency DC-DC converter, the $K_{p}$ and $K_{i}$ values of outer loop are 0.0074 and 0.062 , respectively, and those for boost DC-DC converter are 0.0039 and 2.87, respectively. The tuning of these parameters is obtained using the Ziegler-Nichols method. The inner loop parameters of the PI controller for both of these converters are ten times faster than outer voltage control loop.

Figure 10 represents the schematic diagram of the droop index control. The high step-up DC-DC converter, highgain high-efficiency DC-DC converter, and DC-DC boost converter follow the same structure.

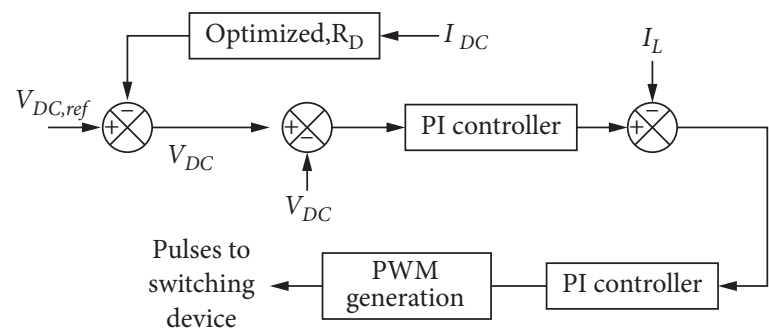

Figure 10: Droop index control diagram.

3.6. Loss of Power Supply Probability (LPSP). The probability of loss of power supply is considered here as a metric to measure the reliability of a system. It is the ratio of the difference of energy demand and energy supply to the total amount of energy demanded by the loads over a period of time. The corresponding expression of LPSP for the system under study is given by equation (31) [33]. The numerator in the expression of LPSP indicates the energy deficit.

LPSP $=\frac{\sum_{t=1}^{T}\left(P_{\text {load }}(t)-P_{p v}(t)-P_{\text {BESS }}(t)-P_{\text {grid }}(t)\right) \Delta t}{\sum_{t=1}^{T} P_{\text {load }}(t) \Delta t}$, 
where $P_{\text {load }}$ is the load demand, $P_{p v}, P_{\mathrm{BESS}}$, and $P_{\text {grid }}$ are the sources of power supply, and $T$ is the period.

\section{Result and Analysis}

Solar PV-fed two interconnected $400 \mathrm{~V}$ and $200 \mathrm{~V}$ DC microgrids are considered to be integrated with CL, NCL, battery, and utility grid for this case study. At $400 \mathrm{~V}$ bus, each $\mathrm{PV}$ source is rated at $4.8 \mathrm{~kW}$ and the BESS rating is $0.8 \mathrm{~kW}$. A static load, dynamic load, and CPL of $6 \mathrm{~kW}, 3.04 \mathrm{~kW}$, and $3.36 \mathrm{~kW}$ are connected, respectively, to a $400 \mathrm{~V}$ bus. Similarly, at $200 \mathrm{~V}$ bus, each PV source is rated at $1 \mathrm{~kW}$ and the BESS rating is $0.4 \mathrm{~kW}$. As in the $400 \mathrm{~V}$ bus, the DC bus of $200 \mathrm{~V}$ is equipped with static load, dynamic load, and CPL of ratings $0.96 \mathrm{~kW}, 0.48 \mathrm{~kW}$, and $0.56 \mathrm{~kW}$, respectively. Solar radiation is assumed to be constant at $1000 \mathrm{~W} / \mathrm{m}^{2}$ during the entire simulation period on both buses under normal conditions. This system is integrated with the utility grid on the $400 \mathrm{~V}$ bus side. To fulfill the energy demands of both NCL and CL at the DC buses, the utility grid also needs to inject power to a $400 \mathrm{~V}$ bus in steady condition along with solar PV.

Two case studies are conducted here to establish the effectiveness of the proposed approach such that bus voltage is maintained at the required level along with the testing of the resilient nature of the grid under such undesired conditions.

Case (i). Impact of utility grid outage at $400 \mathrm{~V}$ bus: simulation study is carried out for $2000 \mathrm{~s}$. During 0-900 s, DC microgrid operates under normal operating conditions, whereas from 900 to $1800 \mathrm{~s}$, a utility grid outage is created, and again at $1800 \mathrm{~s}$, the utility grid is restored to normal. The study shows the improvement of the voltage at the DC bus with the proposed strategy in comparison to the conventional strategy, and at the same time, the system shows its ability to fulfill the demand of the CL under this grid outage condition, hence addressing resiliency.

Case (ii). Effect of poor climatic condition on both the buses and utility grid outage at $400 \mathrm{~V}$ bus: due to change in climatic conditions, solar radiation may reduce. Here, in the second case, the solar radiation is around $300 \mathrm{~W} / \mathrm{m}^{2}$ from the inception of the simulation. Hence, the power generated by PV decreases on both buses. The severity of the condition is further increased by considering the utility grid outage from the $400 \mathrm{~V}$ bus as in Case (i). The total simulation time is the $2000 \mathrm{~s}$, and the grid outage occurs at $900 \mathrm{~s}$ and is restored at $1800 \mathrm{~s}$ as before. This case study shows the better voltage regulation of the DC bus; also, the system proves its resiliency as far as the continuous supply to $\mathrm{CL}$ is concerned. The severity in the system demands the extra available power from the $200 \mathrm{~V}$ bus to be transferred to the $400 \mathrm{~V}$ bus through the high-efficiency bidirectional converter. The analysis and detailed discussion of the aforementioned case studies are presented in the following.
4.1. Observation and Analysis of Case (i). The utility grid supplies a $7 \mathrm{~A}$ current to $400 \mathrm{~V}$ DC bus for the fulfillment of the loads (both NCL and CL) on that bus. At $900 \mathrm{~s}$, grid outage is created and a controlled disconnection of NCLs is started based on the availability of energy sources integrated to DC bus, thus maintaining bus voltage within the desired limit. Again at $1800 \mathrm{~s}$, the utility grid is restored and continues to supply $7 \mathrm{~A}$ as before. Figure 11 shows the utility grid current, feeding to a 400V DC bus.

The proposed droop index control method, with the optimized droop coefficient of value $1.772 \Omega$, gives an improved voltage of the DC microgrid when compared with that by the conventional method (MPPT-based controller). The output voltage of the high step-up converter is around $381 \mathrm{~V}$ with the conventional method, whereas with the droop controller, this value improved to $395 \mathrm{~V}$ as evident from Figure 12(a).

It may be noticed from the figure that this improved voltage is maintained throughout the simulation period, i.e., under normal, grid outage, and grid restoration conditions. The output current and power of each high step-up converter are displayed in Figures 12(b) and 12(c), respectively. It may be observed that each of the converters delivers a current of $12 \mathrm{~A}$, whereas the output power is $4.56 \mathrm{~kW}$. These values remain unchanged even during the grid outage (900s-1800 s) or after grid restoration (beyond $1800 \mathrm{~s}$ ). The CLs on the $400 \mathrm{~V}$ DC bus are a few of the static loads, dynamic loads, and CPLs and consume $30 \%$ of the total load current.

The currents taken by each of these loads are $2 \mathrm{~A}, 3.8 \mathrm{~A}$, and $4.2 \mathrm{~A}$, respectively, as visible in Figures 13(a)-13(c). Considering the importance of $\mathrm{CL}$, they are connected throughout the simulation period irrespective of a grid outage/restoration, thus maintaining resiliency. To keep the DC bus voltage at the desired level even after the grid outage/ restoration, one static load (NCL) consuming $5 \mathrm{~A}$ current is curtailed as given in Figure 14(a). The current supplied to other NCLs, i.e., static load, dynamic load, and CPL, is $8 \mathrm{~A}$, $3.8 \mathrm{~A}$, and $4.2 \mathrm{~A}$ as shown in Figures 14(b)-14(d), respectively.

As under normal conditions, the grid supplies a current of $7 \mathrm{~A}$, reduction of $5 \mathrm{~A}$ current due to NCL curtailment is not enough, and thus the rest of the demand is compensated by a BESS, which supplies $2 \mathrm{~A}$ current.

In absence of a utility grid, the battery works as an auxiliary source to meet the load demand on a $400 \mathrm{~V}$ DC bus. During the grid outage period, the battery current is $20 \mathrm{~A}$, whereas the battery converter current is one-tenth of the battery current, which is $2 \mathrm{~A}$. The variations of these currents are depicted in Figures 15(a) and 15(b), respectively. As the battery is discharging during the simulation period from the $900 \mathrm{~s}$ to $1800 \mathrm{~s}$, the SOC of the battery is reduced from $100 \%$ (assumed fully charged at the beginning of the simulation) to approximately $75 \%$ as shown in Figure 16 . Beyond $1800 \mathrm{~s}$, the battery is disconnected from the circuit and remains on standby.

As the BESS connected to the $400 \mathrm{~V}$ bus alone can take care of the grid outage condition when a part of the static 


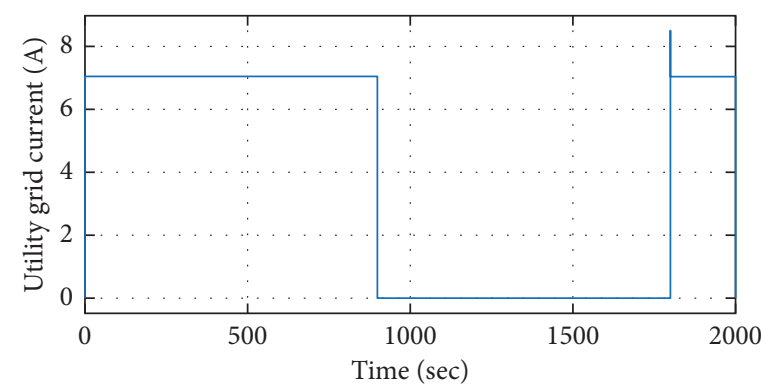

FiguRe 11: Utility grid current.

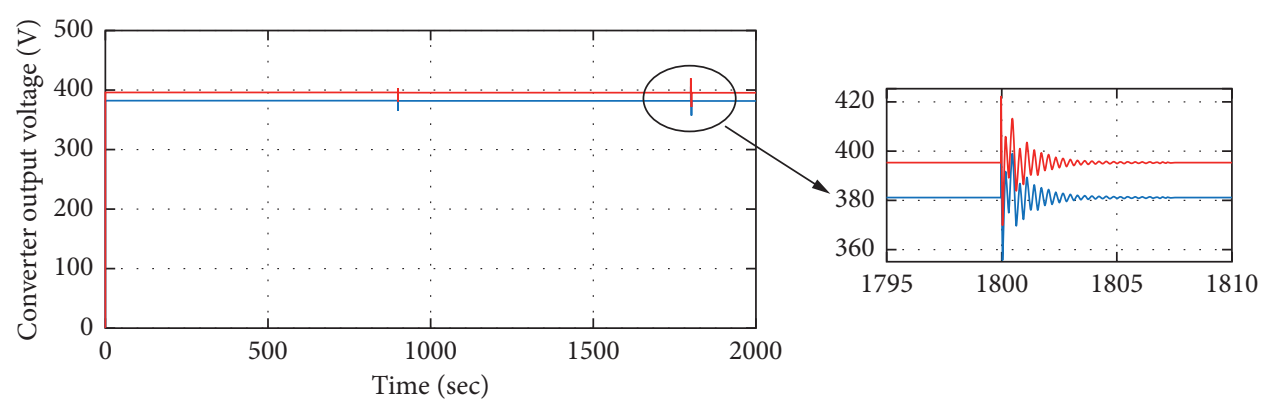

Converter output voltage

(Without droop)

Converter output voltage

(With droop)

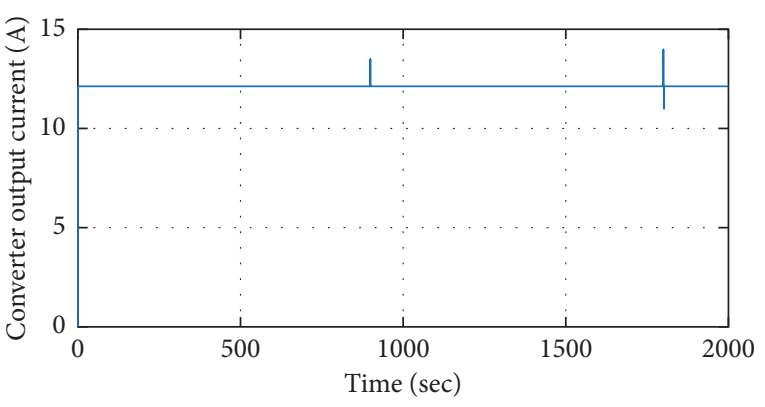

(b) (a)

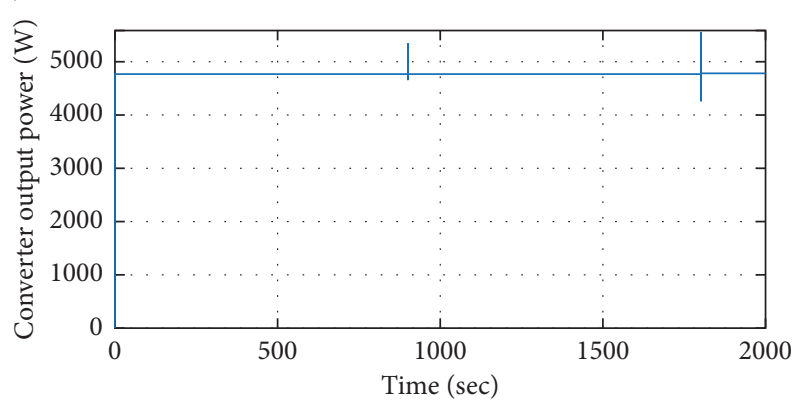

(c)

FIGURE 12: High step-up converter. (a) DC output voltage. (b) DC output current. (c) DC output power.

NCL is curtailed, there is no exchange of power taking place between the two buses in the DC microgrid. The $200 \mathrm{~V}$ bus is operating under normal conditions. The boost converter DC output voltage is about $185 \mathrm{~V}$ with the conventional method and $195 \mathrm{~V}$ with the proposed technique as visible from Figure 17. The boost converter delivers a current of $5 \mathrm{~A}$ each (two solar PVs with corresponding converters are integrated to $200 \mathrm{~V}$ bus in parallel) as shown in Figure 18(a). The total load current of $10 \mathrm{~A}$ (static load: $4.8 \mathrm{~A}$, dynamic load: $2.4 \mathrm{~A}$, and CPL current: $2.8 \mathrm{~A}$ ) is connected to a $200 \mathrm{~V}$ bus as depicted in Figure 18(b).

4.2. Observation and Analysis of Case (ii). This simulation study is started by considering that, due to poor climatic conditions, the solar irradiation is reduced to about $300 \mathrm{~W} /$ $\mathrm{m}^{2}$. At such low solar insolation, the boost converter output voltage of solar PV, connected to $200 \mathrm{~V}$ DC bus, is about $182 \mathrm{~V}$ with the conventional method, whereas with the proposed droop control technique, it is still maintaining $195 \mathrm{~V}$ as in case of normal condition (Section 4.1), proving the superiority of the proposed control strategy over the conventional method. Figure 19(a) shows the boost converter output voltage. The low solar irradiation causes a dip in boost converter current from $5 \mathrm{~A}$ to $1.5 \mathrm{~A}$ (a total of around $3 \mathrm{~A}$ ) from two parallel-connected converters to the $200 \mathrm{~V}$ bus as displayed in Figure 19(b).

The high step-up converter output voltage on the $400 \mathrm{~V}$ bus is around $395 \mathrm{~V}$ with the droop control method, which remains unchanged even during the low solar insolation period, gird outage, and after grid restoration, as shown in Figure 20(a). Due to poor climatic conditions, the solar PV receives insolation of $300 \mathrm{~W} / \mathrm{m}^{2}$, causing the current delivered by solar PV to be $35 \mathrm{~A}$ instead of $120 \mathrm{~A}$. The high 


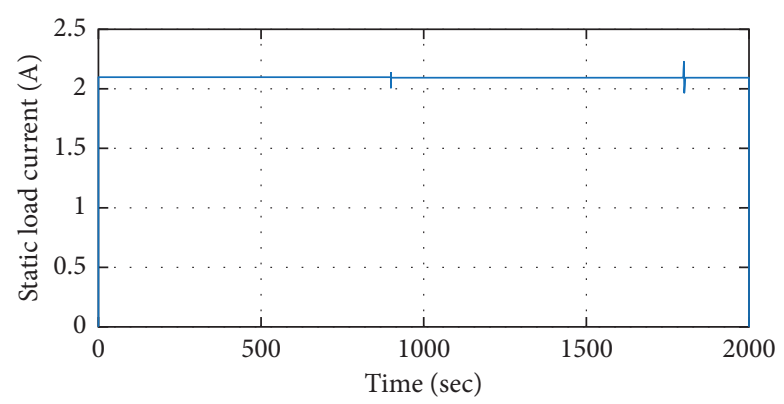

(a)

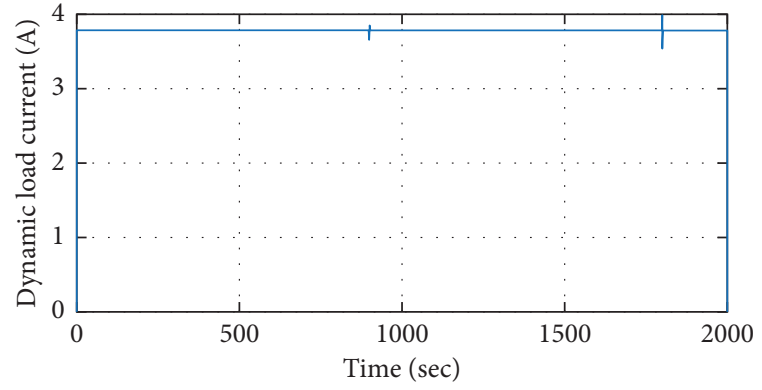

(b)

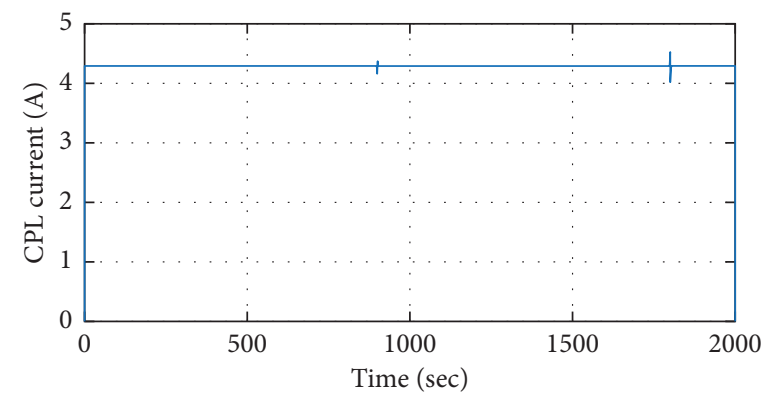

(c)

Figure 13: Critical loads. (a) Static load current. (b) Dynamic load current. (c) CPL current.

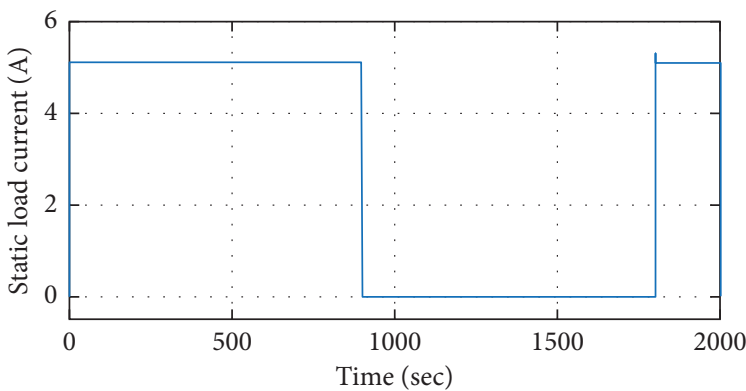

(a)

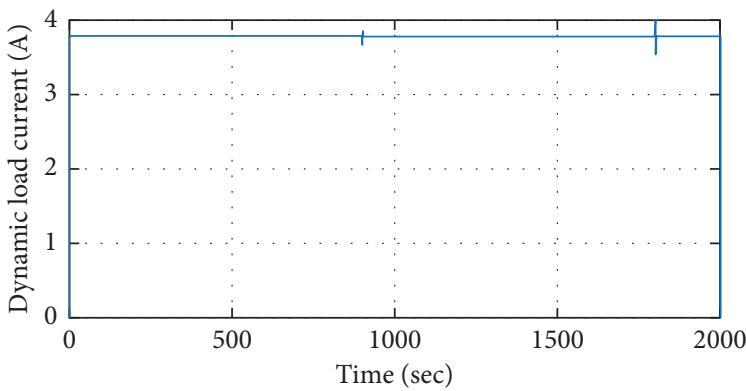

(c)

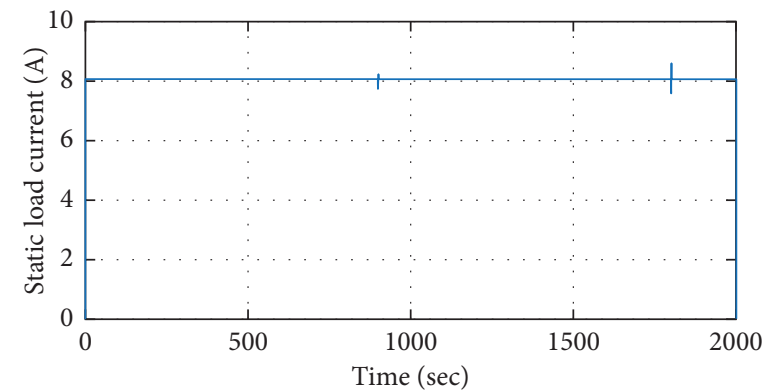

(b)

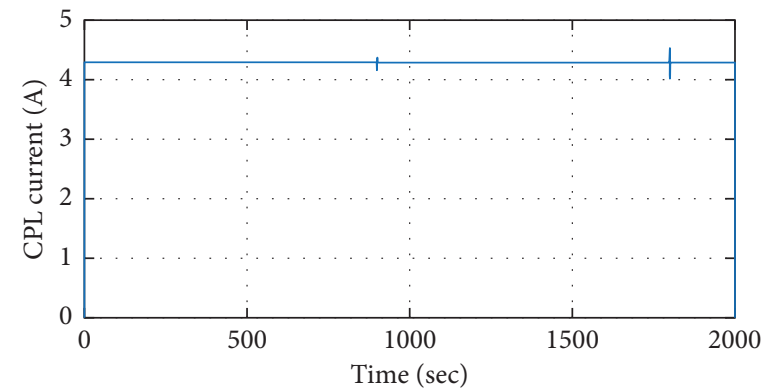

(d)

FIgUre 14: Noncritical loads. (a) Static load current (curtailable). (b) Static load current. (c) Dynamic load current. (d) CPL current.

step-up converter output current is one-tenth of the solar PV current. Therefore, the converter output current is $3.5 \mathrm{~A}$ as demonstrated in Figure 20(b). Hence, the total current supplied by solar PV is $7 \mathrm{~A}$ while the utility grid current is the same as before, i.e., $7 \mathrm{~A}$ (Figure 11). Thus, to satisfy the demand of $14 \mathrm{~A}$, few NCLs are curtailed keeping CLs intact.
The priority during this acute disturbance is to supply energy to CLs on both buses while curtailing NCLs, thereby maintaining the grid voltage at the desired level. The CL of $200 \mathrm{~V}$ microgrid, comprising static and dynamic loads, consumes $30 \%$ of the total load current on this bus which is around $3 \mathrm{~A}$ (around 2.2 $\mathrm{A}$ for dynamic load and $0.8 \mathrm{~A}$ for static load). 


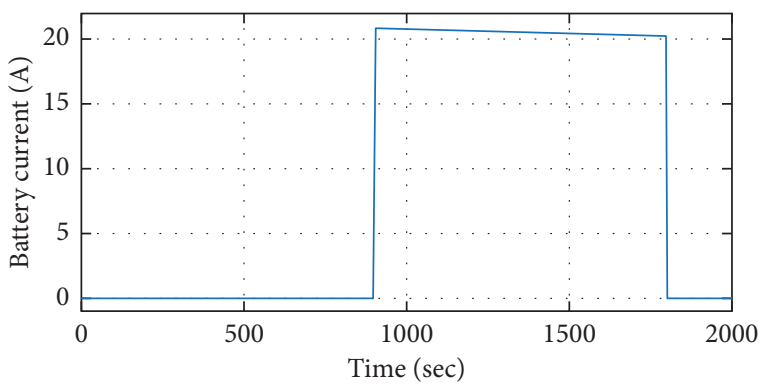

(a)

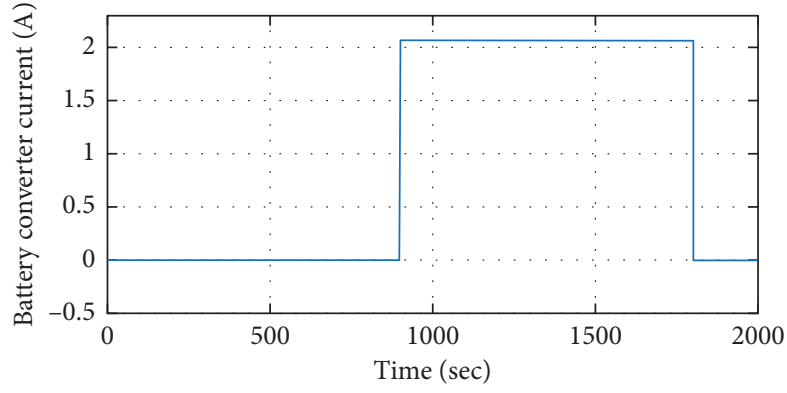

(b)

FIgURE 15: (a) Battery current. (b) Battery converter current.

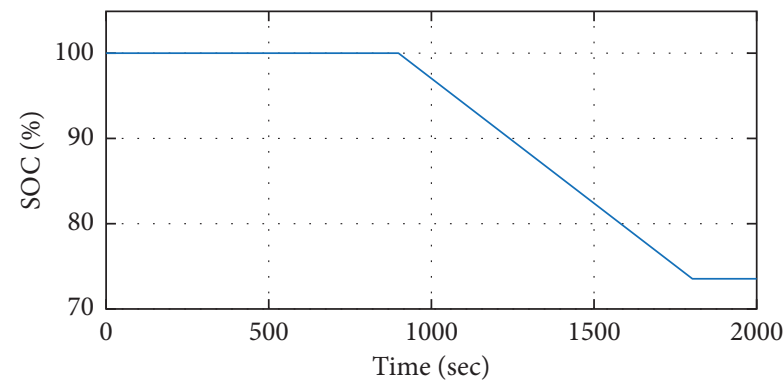

FIGURE 16: SOC versus time.

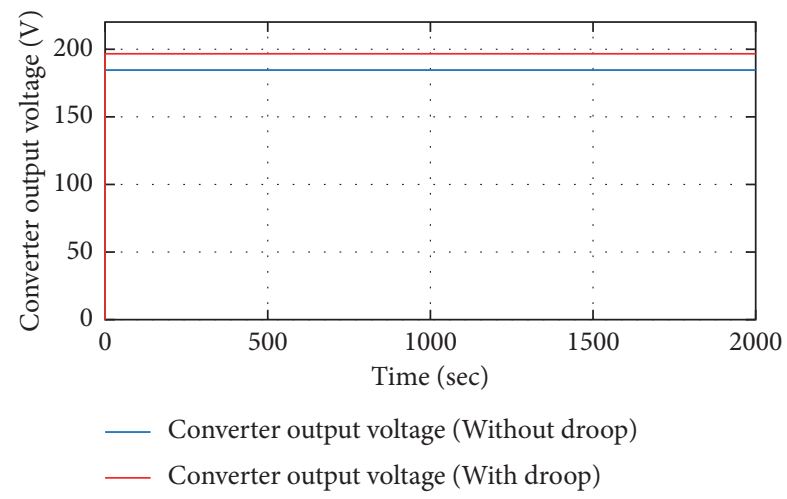

FIGURE 17: Boost converter output voltage.

Figures 21(a) and 21(b) display the plots of static and dynamic load currents, which remain unaffected during low solar insolation, grid outage, and grid restoration. The solar PV connected to the $200 \mathrm{~V}$ bus alone is capable of supplying the CL at its bus. The NCL on the $200 \mathrm{~V}$ bus is static load and $\mathrm{CPL}$, which takes $4 \mathrm{~A}$ and $3 \mathrm{~A}$, respectively. These loads are isolated from the $200 \mathrm{~V}$ bus during the entire simulation period because of low solar insolation.

The utility grid current of $7 \mathrm{~A}$ (to $400 \mathrm{~V}$ bus) reduces to zero under outage conditions (as in Figure 11). It is mentioned earlier that the CL current is $30 \%$ of the total load current in a $400 \mathrm{~V} \mathrm{DC}$ grid with a current share of $10 \mathrm{~A}$ (as may be seen in Figure 13). To have continuous energy supply to the CLs connected to the $400 \mathrm{~V}$ bus, an excess current of $3 \mathrm{~A}$ is needed, out of which BESS integrated to $400 \mathrm{~V}$ bus delivers $2 \mathrm{~A}$ (Section 4.1) while the remaining $1 \mathrm{~A}$ is still a deficit. It is to be mentioned here that the total current demanded by the NCL on $400 \mathrm{~V}$ is shared by static load, dynamic load, and CPL. During the disturbance, all these NCLs are isolated and the values come down to zero for each. The $1 \mathrm{~A}$ deficit current required at the $400 \mathrm{~V}$ bus can be injected by the BESS integrated with the $200 \mathrm{~V}$ bus. The BESS connected to the $200 \mathrm{~V}$ bus starts discharging during the grid outage period (900-1800s) and supplies $20 \mathrm{~A}$ current. The battery converter gives one-tenth of the battery current, that is, $2 \mathrm{~A}$, to the microgrid. This energy of BESS available on $200 \mathrm{~V}$ bus is transferred to $400 \mathrm{~V}$ bus through the high-efficiency bidirectional converter. The current of $2 \mathrm{~A}$ on the $200 \mathrm{~V}$ bus is the input to the bidirectional converter, which is shown in Figure 22(a). The output of the bidirectional converter is about $1 \mathrm{~A}$ as can be seen in Figure 22(b).

4.3. Reliability Index Evaluation. For the period of the simulation study, the reliability of the given system is evaluated as per equation (31). It is clear from Table 9 that for Case (i), during normal/grid restoration, the total amount of power supplied balances the power demanded by the loads; hence, there is no loss of power supply and the system is $100 \%$ reliable, while during grid outage, power supplied by PV $(24 \mathrm{~A}, 395 \mathrm{~V})$ is intact causing LPSP to be $22.54 \%$. To achieve enhanced reliability, additional power is delivered by the BESS $(2 \mathrm{~A}, 395 \mathrm{~V})$, thus enhancing LPSP to be around $16 \%$.

Similarly, for Case (ii) (low insolation), when both PV and grid are intact, total generation is less than the demand causing a deficit of $6.71 \mathrm{~kW}$ and LPSP of $54.82 \%$, whereas under outage condition, the mismatch further increases causing LPSP of $77.45 \%$. It can be improved a bit by inserting a BESS (2 A as before while $1 \mathrm{~A}$ via bidirectional converter), reducing LPSP to $67.72 \%$. Here, the total load includes both CL and NCL. It is to be noted here that in Case (ii), solar insolation is low throughout the simulation study causing energy deficit, and hence to address the resiliency issue, only CLs are considered.

If the calculation of reliability index is carried out by considering only CLs for both the cases, using equation (31), then that would make the value of LPSP to be zero. However, here the values of LPSP are obtained based on connected 


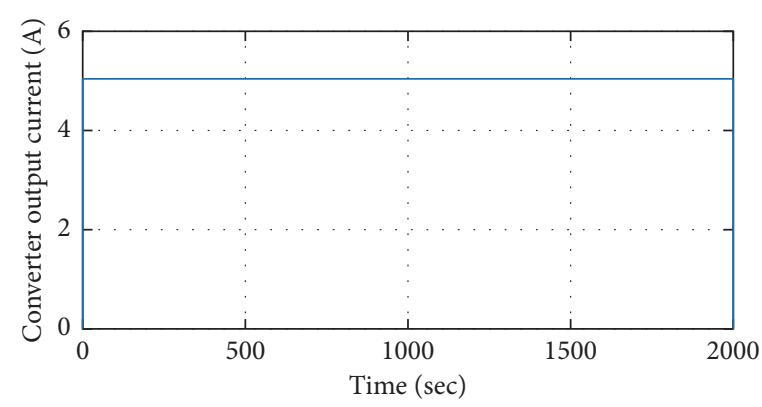

(a)

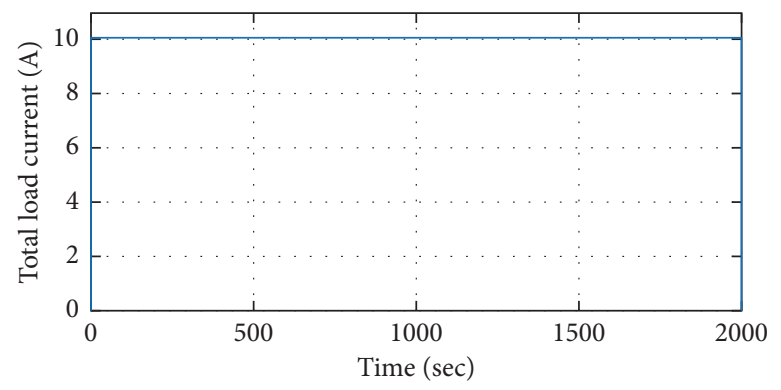

(b)

FIGURE 18: (a) Boost converter output current. (b) Total load current.

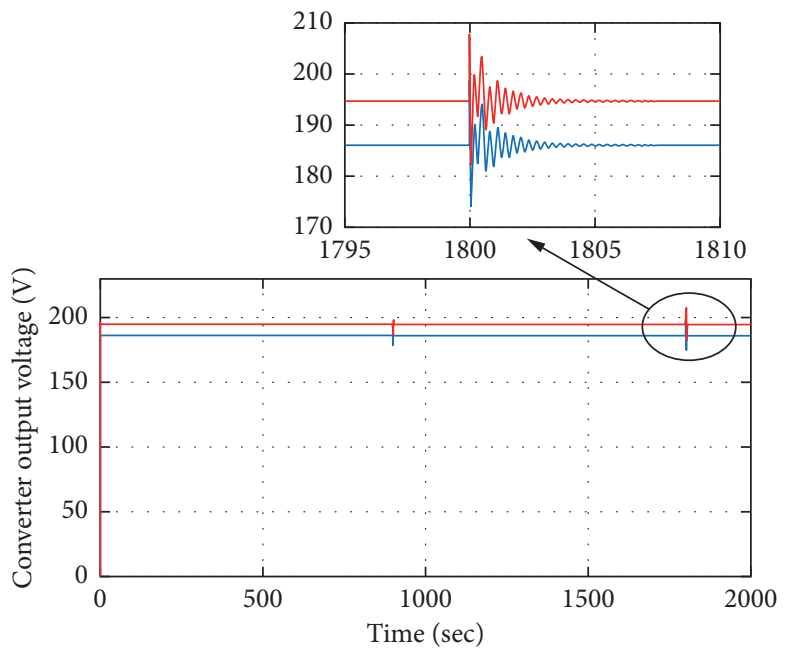

- Converter output voltage (Without droop)

_ Converter output voltage (With droop)

(a)

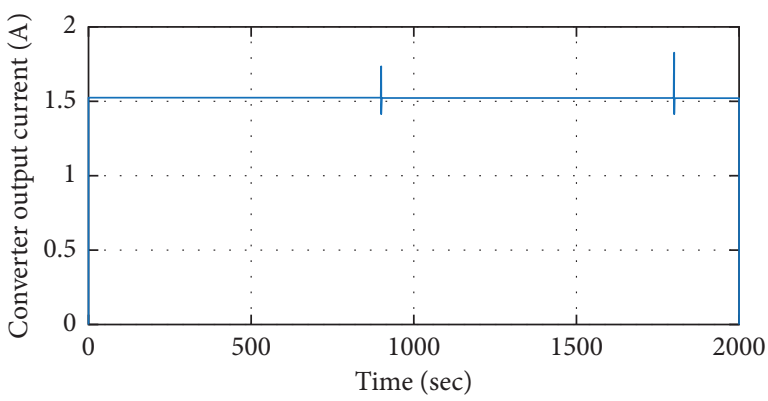

(b)

FIgURE 19: Boost converter. (a) DC output voltage. (b) DC output current.

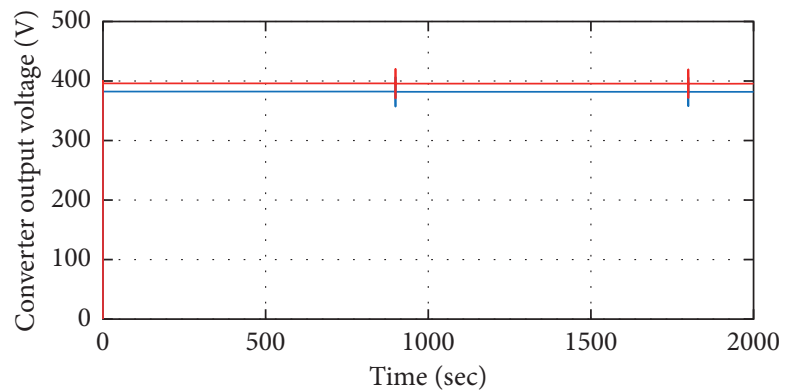

- Converter output voltage (Without droop)

— Converter output voltage (With droop)

(a)

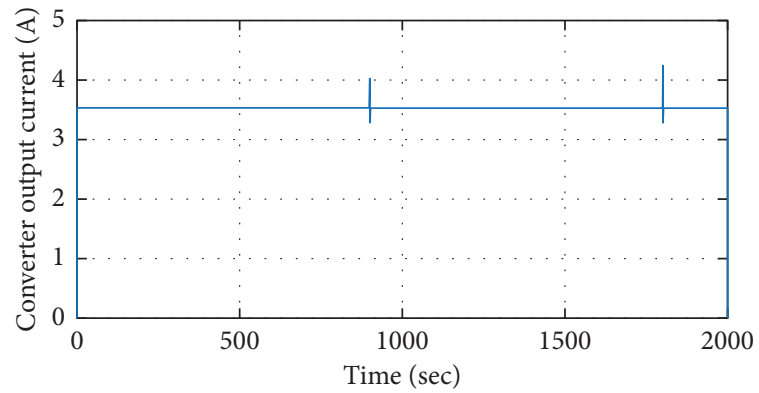

(b)

FIgure 20: High step-up converter. (a) DC output voltage. (b) DC output current.

load, irrespective of CL or NCL, which makes nonzero values of LPSP during the disturbance (grid outage and/or low solar insolation) considered for the study.
The purpose of case studies conducted above for an intergrid DC microgrid is twofold; firstly, under standard insolation, the available energy sources continue to supply 


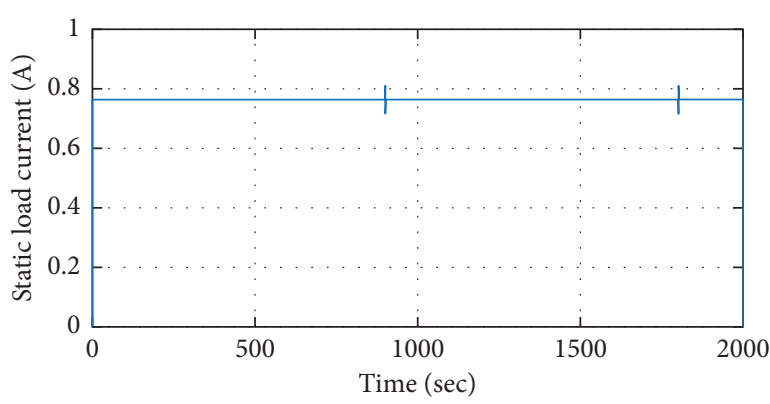

(a)

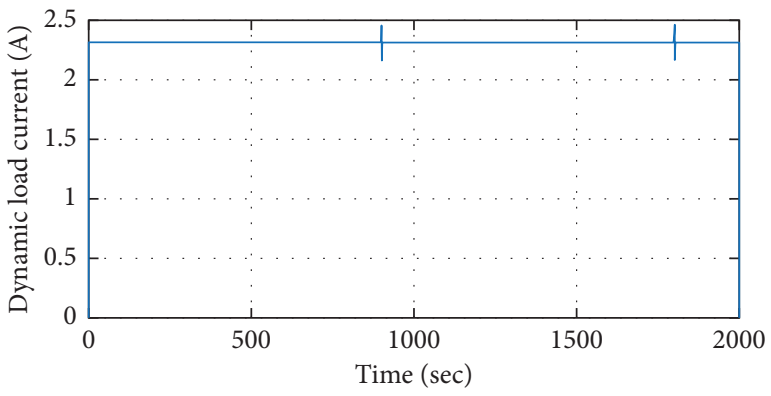

(b)

Figure 21: Critical load. (a) Static load current. (b) Dynamic load current.

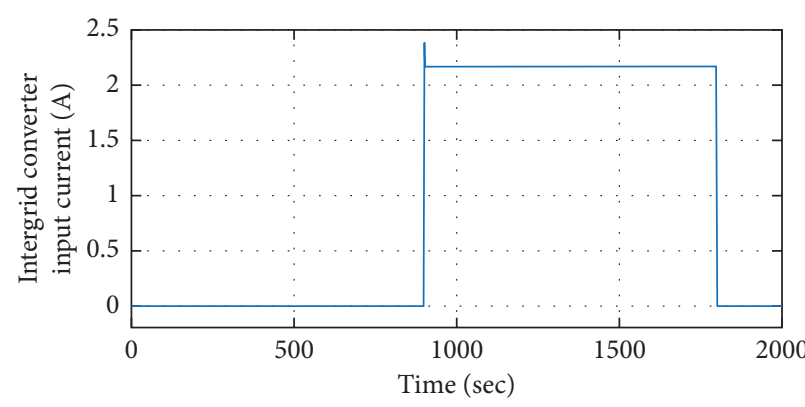

(a)

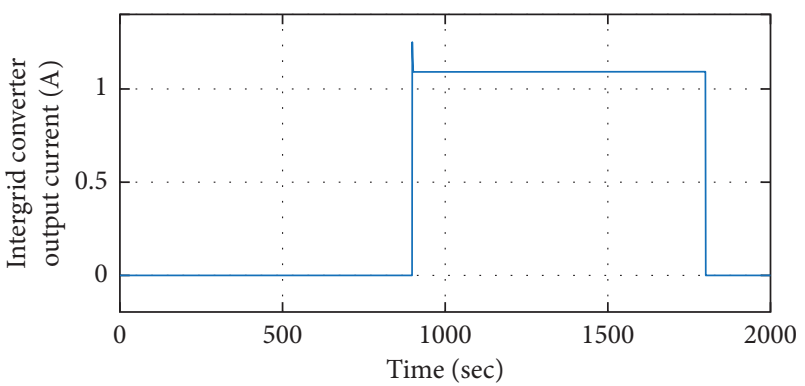

(b)

Figure 22: Intergrid converter. (a) Input current. (b) Output current.

TABLE 9: Reliability index evaluation.

\begin{tabular}{|c|c|c|c|c|c|c|}
\hline \multirow{2}{*}{ Quantities } & \multicolumn{3}{|c|}{ Case (i) $\left[1000 \mathrm{~W} / \mathrm{m}^{2}\right]$} & \multicolumn{3}{|c|}{ Case (ii) $\left[300 \mathrm{~W} / \mathrm{m}^{2}\right]$} \\
\hline & $P_{p v}+P_{\text {grid }}$ & $P_{p v}$ & $P_{p v}+P_{\mathrm{BESS}}$ & $P_{p v}+P_{\text {grid }}$ & $P_{p v}$ & $P_{p v}+P_{\mathrm{BESS}}$ \\
\hline$P_{\text {source }}$ & $12.24 \mathrm{~kW}$ & $9.48 \mathrm{~kW}$ & $10.27 \mathrm{~kW}$ & $5.53 \mathrm{~kW}$ & $2.76 \mathrm{~kW}$ & $3.95 \mathrm{~kW}$ \\
\hline$P_{\text {load }}$ & $1.24 \mathrm{~kW}$ & $12.24 \mathrm{~kW}$ & $12.24 \mathrm{~kW}$ & $12.24 \mathrm{~kW}$ & $12.24 \mathrm{~kW}$ & $12.24 \mathrm{~kW}$ \\
\hline$P_{\text {load }}-P_{\text {source }}$ & 0 & $2.76 \mathrm{~kW}$ & $1.97 \mathrm{~kW}$ & $6.71 \mathrm{~kW}$ & $9.48 \mathrm{~kW}$ & $8.29 \mathrm{~kW}$ \\
\hline LPSP (\%) & 0 & 0.2254 & 0.1609 & 0.5482 & 0.7745 & 0.6772 \\
\hline
\end{tabular}

the majority of the loads with low LPSP, and secondly, under low solar insolation, even though LPSP is high, CLs are prioritized to make sure the system behaves reliably and efficiently. At the same time, the voltage at the two buses is also regulated at its desirable value.

\section{Experimental Results and Analysis}

5.1. Experimental Setup. A hardware prototype of the converter is developed in the laboratory (shown in Figure 23) to validate the performance of a high step-up DC-DC converter with droop control. The Texas Instruments DSP controller "TMS320F283790" has been used for the control of switching pulses of the high step-up DC-DC converter. The parameters and specifications of the laboratory prototype hardware are given in Table 10.

The input and output voltages of the converter are $40 \mathrm{~V}$ and $400 \mathrm{~V}$, respectively, while the input and output currents of the converter are $5 \mathrm{~A}$ and $0.5 \mathrm{~A}$, respectively. The sendust cores with EMS-552825-090 size are used for both inductor and coupled inductor, whereas the type of conductor is litz wire with 200 and 100 strands, respectively.

5.2. Performance of High Step-Up DC-DC Converter under Varying Load Conditions. The designed microgrid consists of a solar PV-based high step-up DC-DC converter. The high step-up converter operates with a switching frequency of $50 \mathrm{kHz}$. The main and auxiliary switch pulses are shown in Figure 24. The time scale is $5 \mu \mathrm{s} /$ div.

Figure 25(a) shows the hardware result of a high stepup DC-DC converter with droop control for a constant load of $800 \Omega$. The output voltage and current of the converter are found to be approximately $400 \mathrm{~V}$ and $0.5 \mathrm{~A}$, respectively.

Again, for the same high step-up converter, the droop controller is tested with changing load currents. The output voltage and current of the high step-up converter are shown in Figure 25(b). The resistive load current is increased from 0.5 A to $0.75 \mathrm{~A}$. During this period (dotted circle), the output 


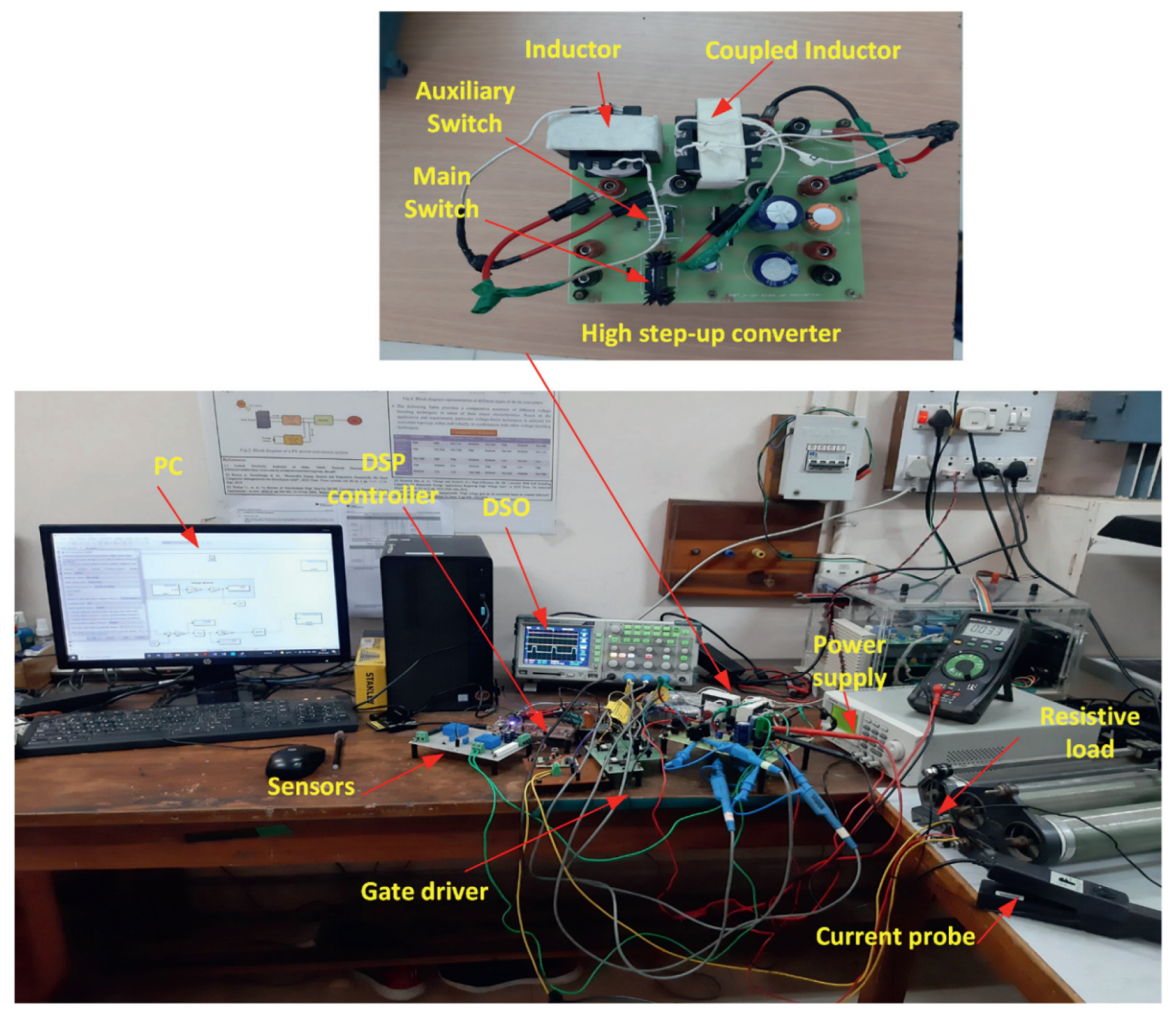

FIGURE 23: Hardware experimental platform of a high step-up DC-DC converter.

TABle 10: Parameters and specifications of the prototype hardware.

\begin{tabular}{lcc}
\hline Symbol & Parameter & Value \\
\hline$V_{\mathrm{PV}}$ and $V_{\mathrm{DC}}$ & Input and output voltages & $40 \mathrm{~V}, 400 \mathrm{~V}$ \\
$P_{\mathrm{DC}}$ & Output power & $200 \mathrm{~W}$ \\
$L_{\mathrm{in}}$ & Input inductor & $400 \mu \mathrm{H}$ \\
$L_{m}$ & Magnetizing inductance & $200 \mu \mathrm{H}$ \\
$L_{k}$ & Leakage inductance & $3.1 \mu \mathrm{H}$ \\
$N_{s} / N_{p}$ & Number of turns & $17 / 12$ \\
$C_{b}$ and $C_{c}$ & Blocking and clamp capacitors \\
$C_{m}$ and $C_{O}$ & Switched and output capacitors & $100 \mu \mathrm{F} / 250 \mathrm{~V}, 220 \mu \mathrm{F} / 50 \mathrm{~V}$ \\
$S_{m}$ and $S_{\text {aux }}$ & Main and auxiliary power switches & $47 \mu \mathrm{F} / 450 \mathrm{~V}, 100 \mu \mathrm{F} / 450 \mathrm{~V}$ \\
$D_{m}$ and $D_{\mathrm{o}}$ & Diodes & IRFP460N \\
$f_{s w}$ & Switching frequency & $\mathrm{MUR} 1560$ \\
\hline
\end{tabular}




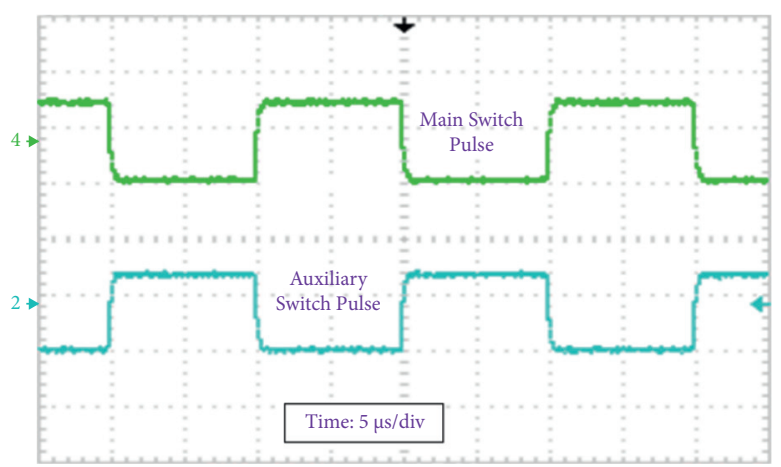

FIgURe 24: Main and auxiliary switch pulses.

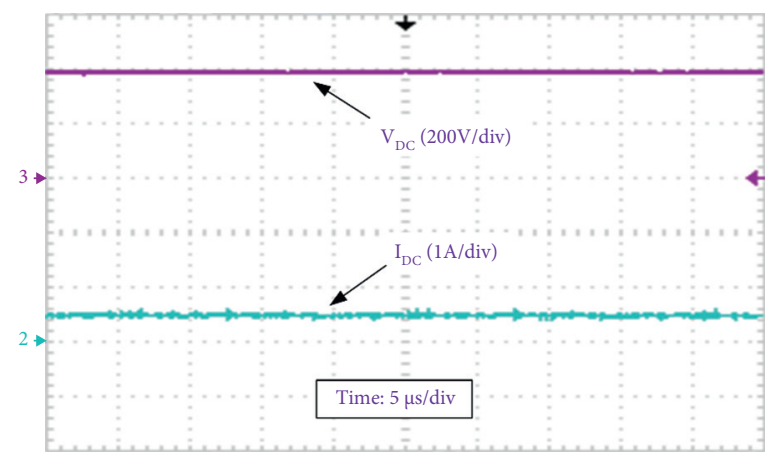

(a)

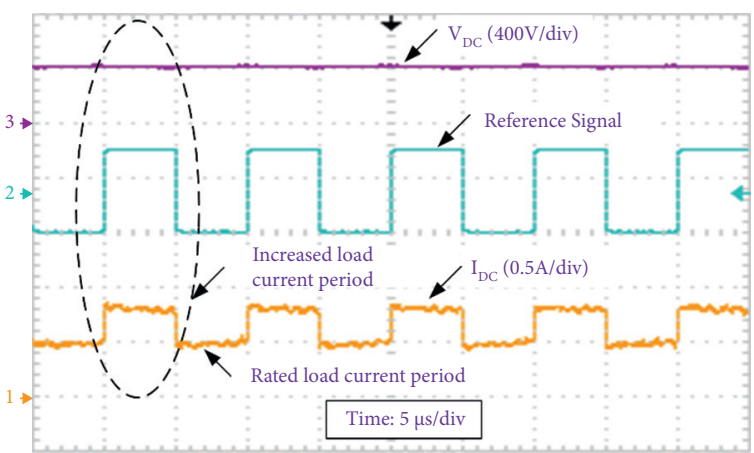

(b)

FIgURE 25: High step-up DC-DC converter output voltage and current. (a) With constant load. (b) With changing loads.

voltage of the converter is maintained at around $400 \mathrm{~V}$, ensuring stable operation of the system. This verifies the simulation result of the study.

\section{Conclusions}

In this work, a resiliency-based approach to the DC microgrid voltage regulation with a high step-up and boost DC-DC converter along with critical and noncritical loads is proposed. This paper also demonstrates a novel framework based on an optimized droop index control method for the solar PV converters. PSO is used to evaluate the optimized value of droop coefficients for each converter resulting in enhanced voltage regulation. The proposed approach is validated and compared with GWO and TLBO.

Simulation studies are conducted with $400 \mathrm{~V}$ and $200 \mathrm{~V}$ buses interconnected via a high-efficiency bidirectional DCDC converter. Both the buses are equipped with CLs and NCLs. In one of the case studies conducted, a utility grid outage is created on a $400 \mathrm{~V}$ bus, which allows curtailment of NCL while CL gets uninterrupted supply by BESS. On the other hand, a more severe condition is introduced with the system already being under stress with low solar radiation and utility grid outage occurring, making the system more resilient to the worst disturbances. This situation causes an exchange of power between the buses via a bidirectional converter. The simulation studies conducted show that the proposed scheme makes the system resilient under several disturbances, aiming to meet the critical load demands and maintain the grid voltage within a desirable range effectively through an optimized droop control technique. Furthermore, the loss of power supply probability index under normal and grid outage scenarios is measured to address the reliability issue.

The effectiveness of the optimized droop index controller is validated with a hardware prototype of a high step-up DCDC converter under varying load conditions.

The present work can be extended for the utilization of different types of renewable energy sources like wind or bio-generation. Moreover, the above system can be analyzed for different durations of utility grid outages as well as various climatic conditions. Also, the proposed approach gives a direction where electric vehicles can be integrated with the existing system and stable operation can be achieved, ensuring local and global energy management cost-effectively. Further, this article aims to motivate fraternity working in this field to adopt clean and green technologies and work towards sustainable development.

\section{Data Availability}

No data were used to support this study.

\section{Conflicts of Interest}

The authors declare that they have no conflicts of interest. 


\section{References}

[1] R. Lasseter, A. Akhil, C. Marnay et al., "Integration of distributed energy resources," The CERTS Microgrid Concept, pp. 1-27, 2002.

[2] E. Hossain, E. Kabalci, R. Bayindir, and R. Perez, "A comprehensive study on microgrid technology," International Journal of Renewable Energy Resources, vol. 4, no. 4, pp. 1094-1104, 2014.

[3] K. Shimomachi, R. Hara, and H. Kita, "Comparison between DC and AC microgrid systems considering ratio of DC load," in Proceedings of the 2015 IEEE PES Asia-Pacific Power and Energy Engineering Conference (APPEEC), pp. 1-4, IEEE, Brisbane, Australia, November 2015.

[4] A. Gupta, S. Doolla, and K. Chatterjee, "Hybrid AC-DC microgrid: systematic evaluation of control strategies," IEEE Transactions on Smart Grid, vol. 9, no. 4, pp. 3830-3843, 2018.

[5] Y. Wang, A. O. Rousis, and G. Strbac, "Resilience-driven modeling, operation and assessment for a hybrid AC/DC microgrid," IEEE Access, vol. 8, pp. 139756-139770, 2020.

[6] S. Pamu, R. Thogaru, and A. Mitra, "Resiliency analysis of grid connected solar PV system with battery support," in Proceedings of the 2020 IEEE First International Conference on Smart Technologies for Power, Energy, and Control (STPEC), pp. 1-6, IEEE, Nagpur, India, September 2020.

[7] G. H. Reddy, P. Chakrapani, A. K. Goswami, and N. B. D. Choudhury, "Optimal distributed generation placement in distribution system to improve reliability and critical loads pick up after natural disasters," Engineering Science and Technology, an International Journal, vol. 20, no. 3, pp. 825-832, 2017.

[8] B. Fan, S. Guo, J. Peng, Q. Yang, W. Liu, and L. Liu, "A consensus-based algorithm for power sharing and voltage regulation in DC microgrids," IEEE Transactions on Industrial Informatics, vol. 16, no. 6, pp. 3987-3996, 2020.

[9] J. Sun, W. Lin, M. Hong, and K. A. Loparo, "Voltage regulation of DC-microgrid with PV and battery," IEEE Transactions on Smart Grid, vol. 11, no. 6, pp. 4662-4675, 2020.

[10] A. C. Gomes, A. S. C. Campos, L. A. C. Lopes, A. S. Morais, F. L. Tofoli, and F. V. R. Silva, "Analysis of a static model for DC microgrids based on droop and MPPT control," International Transactions on Electrical Energy Systems, vol. 29, no. 4, Article ID e2778, 2019.

[11] S. Sahoo, S. Mishra, S. Jha, and B. Singh, "A cooperative adaptive droop based energy management and optimal voltage regulation scheme for DC microgrids," IEEE Transactions on Industrial Electronics, vol. 67, no. 4, pp. 2894-2904, 2020.

[12] M. A. Hassan, E.-p. Li, X. Li, T. Li, C. Duan, and S. Chi, "Adaptive passivity-based control of $\mathrm{dc}$-dc buck power converter with constant power load in DC microgrid systems," IEEE Journal of Emerging and Selected Topics in Power Electronics, vol. 7, no. 3, pp. 2029-2040, 2019.

[13] J. Kathiresan, S. K. Natarajan, and G. Jothimani, "Energy management of distributed renewable energy sources for residential DC microgrid applications," International Transactions on Electrical Energy Systems, vol. 30, no. 3, 2020.

[14] M. Forouzesh, Y. Shen, K. Yari, Y. P. Siwakoti, and F. Blaabjerg, "High-efficiency high step-up DC-DC converter with dual coupled inductors for grid-connected photovoltaic systems," IEEE Transactions on Power Electronics, vol. 33, no. 7, pp. 5967-5982, 2018.

[15] A. M. S. S. Andrade, L. Schuch, and M. L. da Silva Martins, "Analysis and design of high-efficiency hybrid high step-up
DC-DC converter for distributed PV generation systems," IEEE Transactions on Industrial Electronics, vol. 66, no. 5, pp. 3860-3868, 2019.

[16] W. Hassan, J. L. Soon, D. Dah-Chuan Lu, and W. Xiao, “A high conversion ratio and high-efficiency bidirectional DC-DC converter with reduced voltage stress," IEEE Transactions on Power Electronics, vol. 35, no. 11, pp. 11827-11842, 2020.

[17] B. Sri Revathi, M. Prabhakar, and F. Gonzalez-Longatt, "Highgain-high-power (HGHP) DC-DC converter for DC microgrid applications: design and testing," International Transactions on Electrical Energy Systems, vol. 28, no. 2, Article ID e2487, 2018.

[18] A. H. Fathima and K. Palanisamy, "Optimization in microgrids with hybrid energy systems-a review," Renewable and Sustainable Energy Reviews, vol. 45, pp. 431-446, 2015.

[19] S. Phommixay, M. L. Doumbia, and D. Lupien St-Pierre, "Review on the cost optimization of microgrids via particle swarm optimization," International Journal of Energy and Environmental Engineering, vol. 11, no. 1, pp. 73-89, 2020.

[20] E. D. Collins and B. Ramachandran, "Power management in a microgrid using teaching learning based optimization algorithm," in SoutheastCon 2017, pp. 1-6, IEEE, Piscataway, NJ, USA, 2017.

[21] J. D. Irwin, Power Electronics Handbook, Academic Press, Cambridge, MA, USA, 2011, http://www.sciencedirect.com/ science/article/pii/B978012382036500001X.

[22] D. Srujan, R. Thogaru, A. Mitra, and V. B. Borghate, "Energy management in grid assisted BESS integrated solar PV based smart charging station," in Proceedings of the IECON 2019-45th Annual Conference of the IEEE Industrial Electronics Society, pp. 6363-6368, IEEE, Lisbon, Portugal, October 2019.

[23] A. Mirzaee and J. S. Moghani, "Coupled inductor-based high voltage gain DC-DC converter for renewable energy applications," IEEE Transactions on Power Electronics, vol. 35, no. 7, pp. 7045-7057, 2020.

[24] M. P. Shreelakshmi, M. Das, and V. Agarwal, "Design and development of a novel high voltage gain, high-efficiency bidirectional DC-DC converter for storage interface," IEEE Transactions on Industrial Electronics, vol. 66, no. 6, pp. 4490-4501, 2019.

[25] J.-G. Kim, S.-W. Park, Y.-H. Kim, Y.-C. Jung, and C.-Y. Won, "High-efficiency bidirectional soft switching DC-DC converter," in Proceedings of the 2010 International Power Electronics Conference (ECCE ASIA), pp. 2905-2911, IEEE, Sapporo, Japan, June 2010.

[26] S. Chakraborty, P. Arvind, and D. Kumar, "Integrated solar PV MPPT and V-f control for stand-alone microgrid," in Proceedings of the 2019 International Conference on Electrical, Electronics and Computer Engineering (UPCON), pp. 1-6, IEEE, Aligarh, India, November 2019.

[27] P.-H. Huang, P.-C. Liu, W. Xiao, and M. S. El Moursi, “A novel droop-based average voltage sharing control strategy for DC microgrids," IEEE Transactions on Smart Grid, vol. 6, no. 3, pp. 1096-1106, 2015.

[28] M. Clerc, Particle Swarm Optimization, ISTE, New Delhi, India, 2006.

[29] D. R. Shivam, "Voltage regulation and enhance load sharing in DC microgrid based on particle swarm optimization in marine applications," Indian Journal of Geo-Marine Sciences, vol. 46, no. 10, pp. 2105-2113, 2017.

[30] S. C. Reddy, S. Muthukumari, T. K. S. Kumar, S. Kumaravel, and S. Kanagalakshmi, "TLBO based droop optimization 
technique for DC microgrid," in Proceedings of the TENCON 2019-2019 IEEE Region 10 Conference (TENCON), pp. 24182423, IEEE, Kochi, India, October 2019.

[31] S. Mirjalili, S. M. Mirjalili, and A. Lewis, "Grey wolf optimizer," Advances in Engineering Software, vol. 69, pp. 46-61, 2014.

[32] S. Augustine, M. K. Mishra, and N. Lakshminarasamma, "Adaptive droop control strategy for load sharing and circulating current minimization in low-voltage standalone DC microgrid," IEEE Transactions on Sustainable Energy, vol. 6, no. 1, pp. 132-141, 2015.

[33] R. Ayop, N. M. Isa, and C. W. Tan, "Components sizing of photovoltaic stand-alone system based on loss of power supply probability," Renewable and Sustainable Energy Reviews, vol. 81, pp. 2731-2743, 2018.

[34] M. Salah and M. Abdelati, "Parameters identification of a permanent magnet DC motor," in Modelling, Identification, and Control, pp. 177-182, ACTA Press, Calgary, Canada, 2010.

[35] R. b. Thogaru and A. Mitra, "Voltage stability and loadability improvement of DC microgrid connected with static and dynamic loads," in Proceedings of the 2019 IEEE 5th International Conference for Convergence in Technology (I2CT), pp. 1-5, IEEE, Bombay, India, October 2019. 